\title{
Welfare Effects of Tax and Price Changes Revisited
}

Knud J. Munk

Discussion Paper 2008-6

\section{Département des Sciences Économiques de l'Université catholique de Louvain}




\title{
Welfare Effects of Tax and Price Changes Revisited
}

\author{
Knud J. Munk ${ }^{\dagger}$ \\ Université catholique de Louvain and University of Aarhus
}

This version: January 2008

\begin{abstract}
Dixit's 1975 paper "Welfare Effects of Tax and Price Changes" constitutes a seminal contribution to the theory of tax reform analysis within a second-best general equilibrium framework. The present paper clarifies ambiguities with respect to normalisation which have led to misinterpretation of some of Dixit's analytical results. It proves that a marginal tax reform starting from a proportional tax system will improve social welfare if it increases the supply of labour, whatever the rule of normalisation adopted, and shows that this result provides the key to understanding what determines the optimal system of commodity taxation as reflected in the Corlett and Hague analysis of optimal taxation in an economy with two produced commodities. Recasting work by Deaton (1981b), it generalises, using an alternative definition of the complementarity between consumption and leisure, to an economy with many commodities the insight that the optimal tax system is determined as a trade-off between two objectives: 1) to encourage the supply of labour to the market, and 2), to limit the distortion of the pattern of consumption of produced commodities. This insight cannot be illustrated by simulation studies using standard additive separable utility functions. However, extending work of Atkinson and Stern $(1980,1981)$ the paper presents a parameterised utility function with explicit representation of the use of time, the CES-UT, which allows a flexible representation of the relationship between consumption and leisure. This functional form is used to provide a quantitative illustration of the trade-off which defines the optimal tax system and thus desirable directions of tax reform.
\end{abstract}

\section{Keywords:}

Public economics, optimal taxation, tax reform, tax simulation, distance functions, CGE models

\section{JEL classification codes:}

$\mathrm{H} 2$

\section{Acknowledgements:}

Previous versions of this paper has been presented at the $57^{\text {th }}$ Congress of the International Institute of Public Finance, Linz August 2001, at EPRU, University of Copenhagen, October 2001; at the Nordic Workshop on Tax Policy and Public Economics in Uppsala November 2001, at the ECOMOD conference in Istanbul 2005 and at the 2007 Congress of the APET in Nashville, US. I would like to thank participants in these events for valuable comments. Comments by Inger Munk and Peter Norman Sørensen have also been very helpful. The initial work for this paper was undertaken at the Economic Policy Research Unit (EPRU), Institute of Economics, University of Copenhagen and at the Center of Economic Studies (CES), Department of Economics, University of Leuven, Belgium during the period 1.3. 1998-1.9. 2000 funded by Research Grant no 9800070 from the Danish Social Science Research Council. The research has also benefited from resources that have been made available by the Institute of Economics at University of Copenhagen and the Department of Economics at the University of Leuven, and in the final phase of the work by Université catholique de Louvain and University of Aarhus.

\footnotetext{
${ }^{\dagger}$ Visiting Professor at UCL and Adjunct Associate Professor at University of Aarhus. He is also Research Professor at DIW and Associate Senior Research Fellow at the Danish Technical University. Correspondence: knud.munk@uclouvain.be
} 


\section{Introduction}

Dixit's (1975) seminal paper "Welfare Effects of Tax and Price Changes" constitutes an seminal and important contribution to the general equilibrium approach to optimal tax analysis. Furthermore, from the start of the development of the theory of optimal taxation in the 1970s, simulation studies have been used as a way to provide such insight. However, the policy implications of Dixit's analytical results have remained elusive.

We suggest two reasons (among others) for this. First, the ambiguity in the specification of rules of normalisation in Dixit's original contributions from 1975 (and 1970) seems to have provided a barrier to the recognition of the importance for desirable directions of tax reform of the interaction between the consumption of purchased commodities and the untaxed use of the primary factor ("leisure"). Second, the straitjacket imposed on the representation of household behaviour in simulation studies by the generalised application of additive separable utility functions which has made it impossible to represent this interaction.

The purpose of this paper is double: first, to reinterpret Dixit's analysis; second, to provide an alternative to the functional forms widely used in Computable General Equilibrium models and other applied work. Methodologically, the paper is rooted in the contributions by Dixit (1975, op. cit), Dixit and Munk (1977) and Munk (1978, 1980) which emphasise the importance of a full articulation of the general equilibrium assumptions and the advantages of using a dual approach as the basis for tax reform and optimal tax analysis. More generally the analysis is embedded in the modern theory of optimal taxation established in the 1970s by Mirrlees, Stiglitz, Atkinson, Stern, Dixit, Deaton, Sandmo and others. Specifically it draws inspiration from, and builds on Atkinson and Stern $(1980,1981)$. Their starting point was, as here, the limitation of tax simulations studies based on additive separable functional forms. Based on the observation that goods are usually purchased for use in particular activities, and that these activities involve the use of time, they proposed the use of utility functions based on the explicit representation of the use of time to assess the consequences of the introduction of a VAT.

We first specify three alternative interpretations of the model formulated in Dixit (1975,) and on this basis generalise Proposition 1 in Munk (1978) concerning the rules of normalisation in such models. Furthermore, based only on formulations of the conditions for general equilibrium under alternative assumptions about the tax base, we provide an intuitive insight into what determines desirable direction of tax reform and optimal commodity taxation. On this basis we identify ambiguities in Dixit's model formulation. Using an alternative rule of normalisation, but the same method of analysis, we reformulate two theorems in Dixit (1975, op. cit.).

Secondly, with the same motivation as Atkinson and Stern $(1980,1981)$, we show how the explicit representation of the use of time can help to improve the understanding of what constitutes desirable directions of tax reform and also what determines the optimal system of taxation. In an attempt to dispel confusion in the literature on this point, we illustrate, just based on properties of homogeneity of demand functions and profit functions, that incorporating household production in the household's utility function does not modify the results of optimal tax theory. The results of Corlett and Hague's (1953) analysis of optimal taxation is thus valid also with the explicit representation of household productions, even when household production is associated with decreasing returns to scale. In particular we 
show that the presence of shadow profit in household production does not compromise the Diamond-Mirrless Theorem of Production Efficiency, as have been alleged.

Thirdly, we illustrate, recasting work by Deaton (1981b), how insight derived from the Corlett and Hague analysis of optimal taxation in an economy with two produced commodities, can be generalised to an economy with many commodities using an alternative definition of the complementarity between consumption and leisure.

Finally, we analyse the properties of demand systems based on the CES-UT parameterisation of utility functions with the explicit representation of the use of time (see e.g. Munk 1998). The analysis suggests that the use of this functional form can contribute to the deeper understanding of what determines desirable directions of tax reform and systems of optimal taxation. We also demonstrate how, based on the CES-UT specification of household preferences, it is possible to derive a system of demand elasticities which can be compared to estimates calculated by econometric methods. In this context we emphasise that in contrast to utility functions based on the Becker specification, utility functions based on CES-UT parameterisation imply that commodities which require relative large amount of time for their consumptions are not necessarily complementary with the untaxed use of labour ("Leisure") and for that reason should not necessarily attract relative high rates of taxation.

In the process we relate the results to the existing literature.

\section{The setting}

Following Dixit (1975, op.cit.), we consider a competitive economy with one representative household and a government, where there is one primary factor, labour, labelled 0 , and $\mathrm{N}$ produced commodities labelled $1, \ldots, \mathrm{N}$. We denote the set of commodities $F C$ and the set of produced commodities $C$. The household's vector of endowments is $\boldsymbol{\omega} \equiv\left(\omega_{0}, 0, \ldots, 0\right)$, its vector of consumptions $\mathbf{c} \equiv\left(c_{0}, c_{1}, . . c_{N}\right)$, and its net trade vector thus $\mathbf{x} \equiv\left(x_{0}, x_{1}, ., x_{\mathrm{N}}\right) \equiv \mathbf{c}-\mathbf{\omega}$. The primary factor can best be thought of as time, making $x_{0}$ labour measured negatively, and $c_{0}$ the household's consumption of its time endowment, traditionally referred to as "leisure", but better called "the household's untaxed use of labour". Consumer prices are $\mathbf{q} \equiv\left(q_{0}, q_{1}, . ., q_{N}\right)$ and producer prices are $\mathbf{p} \equiv\left(p_{0}, p_{1}, ., p_{\mathrm{N}}\right)$. The government's resource requirements, $\mathbf{x}^{G} \equiv\left(x_{0}^{\mathrm{G}}, x_{1}^{\mathrm{G}}, ., x_{\mathrm{N}}^{\mathrm{G}}\right)$, are financed by commodity taxes, $\mathbf{t} \equiv \mathbf{q}-\mathbf{p}$. The government's expenditures are thus $G \equiv \mathbf{p}^{\prime} \mathbf{x}^{G}$. The household's preferences are represented by a differentiable, strictly quasi-concave utility function, $u(\mathbf{c})$. Production possibilities are represented by production functions , $y_{i}=f^{i}\left(y_{0}^{i}\right), i=1, . ., \mathrm{N}$, where $y_{i}$ is the production of commodity $i$, and $y_{0}^{i}$ the use of the primary factor in its production, which take the form $y_{i}=a_{0}^{i} y_{0}^{i}, i=1, . ., \mathrm{N}$ when a linear production structure is assumed.

The government's resource requirements, $\mathbf{x}^{G} \equiv\left(x_{0}^{G}, x_{1}^{G}, ., x_{N}^{G}\right)$, are financed by commodity taxes, $\mathbf{t} \equiv \mathbf{q}-\mathbf{p}$. For a tax system, $\mathbf{t}$, to be feasible, i.e. for it to be compatible with a market 
equilibrium, the three basic conditions for Profit maximisation, Utility maximisation and Material balance have to be satisfied, as well as the condition for the government's budget to be balanced and a number of tax-price equations.

In the case of constant returns to scale, the conditions for profit maximization may be expressed as

$$
\begin{array}{lr}
y_{0}^{i}=a_{0}^{i} y_{i} & \mathrm{i} \in \mathrm{C}(1) \\
\mathrm{p}_{\mathrm{i}}=\mathrm{a}_{0}^{\mathrm{i}} \mathrm{p}_{0} & \mathrm{i} \in \mathrm{C}(2)
\end{array}
$$

Using the dual approach, as in Dixit (1975, op. cit) and Dixit and Munk (1977), household behaviour in terms of its choice of net trade, $\mathbf{x} \equiv\left(x_{0}, x_{1}, ., x_{\mathrm{N}}\right)$, may be expressed as ${ }^{1}$

$$
\begin{aligned}
& \mathbf{x}=\mathbf{E}_{\mathbf{q}}(\mathbf{q}, u) \\
& E(\mathbf{q}, u)=0
\end{aligned}
$$

where expenditure function, $E(\mathbf{q}, u)$, is the value function corresponding to the problem $\left\{\min _{\mathbf{x}} \mathbf{q}\right.$ 'x s. t. $\left.u=u(\boldsymbol{\omega}-\mathbf{x})\right\}$.

Material balance requires

$$
\begin{gathered}
y_{i}=x_{i}+x_{i}^{G} \\
0=x_{0}+x_{0}^{G}
\end{gathered}
$$

Assuming that commodity taxation is based on net trade, the government's budget constraint is

$$
\mathbf{t}^{\prime} \mathbf{E}_{\mathbf{q}}(\mathbf{q}, u)=\mathbf{p}^{\prime} \mathbf{x}^{G}
$$

where commodity taxes are

$$
\mathbf{t}=\mathbf{q}-\mathbf{p}
$$

By successive substitution equation (1) to (8) may be reduced to

$$
\begin{aligned}
& \sum_{i \in C}\left(a_{0}^{i} E_{i}(q, u)+x_{i}^{G}\right)+E_{0}(q, u)+x_{0}^{G}=0 \\
& E(\mathbf{q}, u)=0 \\
& \mathbf{t}^{\prime} \mathbf{E}_{\mathbf{q}}(\mathbf{q}, u)=\mathbf{p}^{\prime} \mathbf{x}^{G} \\
& \mathbf{t}=\mathbf{q}-\mathbf{p}
\end{aligned}
$$

\footnotetext{
${ }^{1}$ Using the subscript notation, we write net demand functions, as $\mathbf{E}_{\mathbf{q}}(\mathbf{q}, u) \equiv\left\{x_{i}(\mathbf{q}, u), i \in F C\right\}$ and gross demand functions, as $\mathbf{M}_{\mathbf{q}}(\mathbf{q}, u) \equiv\left\{c_{i}(\mathbf{q}, u), i \in F C\right\}$, and the corresponding partial demand derivatives as $\mathbf{E}_{\mathrm{qq}}(\mathbf{q}, u) \equiv\left\{\frac{\partial x_{k}}{\partial q_{i}}, i, j \in F C\right\}$ and $\mathbf{M}_{\mathrm{qq}}(\mathbf{q}, u) \equiv\left\{\frac{\partial c_{k}}{\partial q_{i}}, i, j \in F C\right\}$.
} 
By Walras' law we can delete (9). Under the assumption that taxation is based on net trade, and that there is no profit (Case 1, Figure 1b), the conditions for $\mathbf{t}$ to correspond to an equilibrium situation may thus be expressed as

$$
\begin{aligned}
& E(\mathbf{q}, u)=0 \\
& \mathbf{t}^{\prime} \mathbf{E}_{\mathbf{q}}(\mathbf{q}, u)=\mathbf{p}^{\prime} \mathbf{x}^{G} \\
& \mathbf{t} \equiv \mathbf{q}-\mathbf{p}
\end{aligned}
$$

Under the alterative assumption that taxation is based on consumption, $\mathbf{c} \equiv\left(c_{0}, c_{1}, ., c_{\mathrm{N}}\right)$, and assuming that there is no profit, (Case 2, Figure 1a) the conditions for $\mathbf{t}$ to correspond to an equilibrium situation may be expressed as

$$
\begin{aligned}
& M(\mathbf{q}, u)=p_{0} \omega_{0} \\
& \mathbf{t}^{\prime} \mathbf{M}_{\mathbf{q}}(\mathbf{q}, u)=\mathbf{p}^{\prime} \mathbf{x}^{G} \\
& \mathbf{t} \equiv \mathbf{q}-\mathbf{p}
\end{aligned}
$$

where $M(\mathbf{q}, u)$ is the full income expenditure function, defined as the value function for the problem $\left\{\min _{\mathbf{c}} \mathbf{q}\right.$ 'c s. t. $\left.u=u(\mathbf{c})\right\}$.

Finally, assuming that taxation is based on net trade, and that the household receives profit income, $I=\Pi(\mathbf{p})>0$, (Case 3, Figure $2 a$ and $2 b$ ), the conditions for $\mathbf{t}$ to correspond to an equilibrium situation become

$$
\begin{aligned}
& E(\mathbf{q}, u)=\Pi(\mathbf{p}) \\
& \mathbf{t}^{\prime} \mathbf{E}_{\mathbf{q}}(\mathbf{q}, u)=\mathbf{p}^{\prime} \mathbf{x}^{G} \\
& \mathbf{t} \equiv \mathbf{q}-\mathbf{p}
\end{aligned}
$$

Equations (13), (16) and (19) requires the level of utility to be consistent with household income, which in Case 2 is the value of the endowment of the primary factor, and in Case 1 and Case 3 the profit associated with production in the formal sector. In Case 1 this is nil. Equations (14), (17), and (20) may be interpreted as the government's budget constraint. In each case the three equations represent all the general equilibrium conditions for $\mathbf{t}$ to be feasible (cf. Dixit and Munk 1977). 
Figure 1a: Taxation of consumption

Consumption of the produced commodity, production

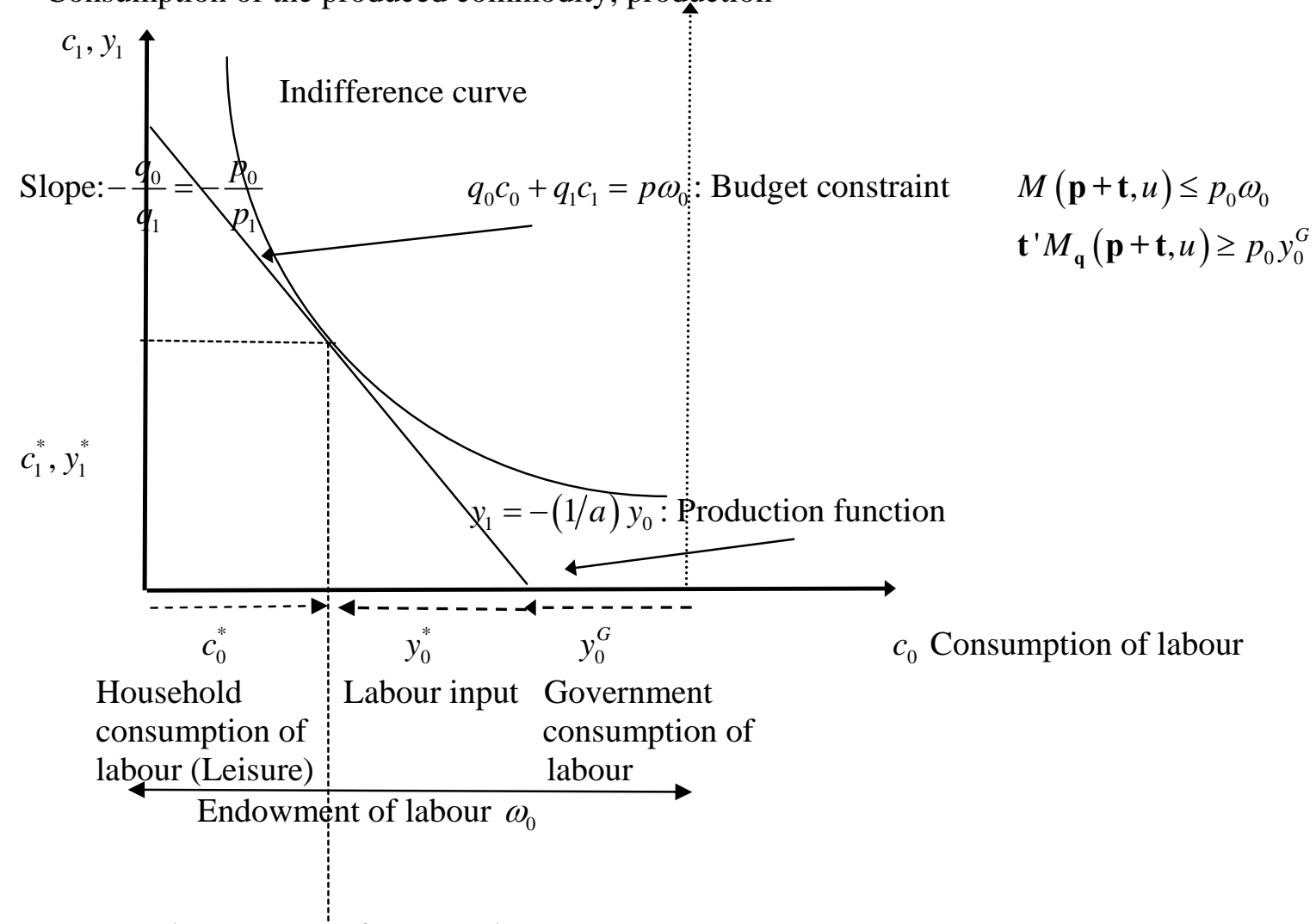

Figure 1b: Taxation of net purchase




Figure 2a: Taxation of net purchases. Value of profit greater than the government's requirement

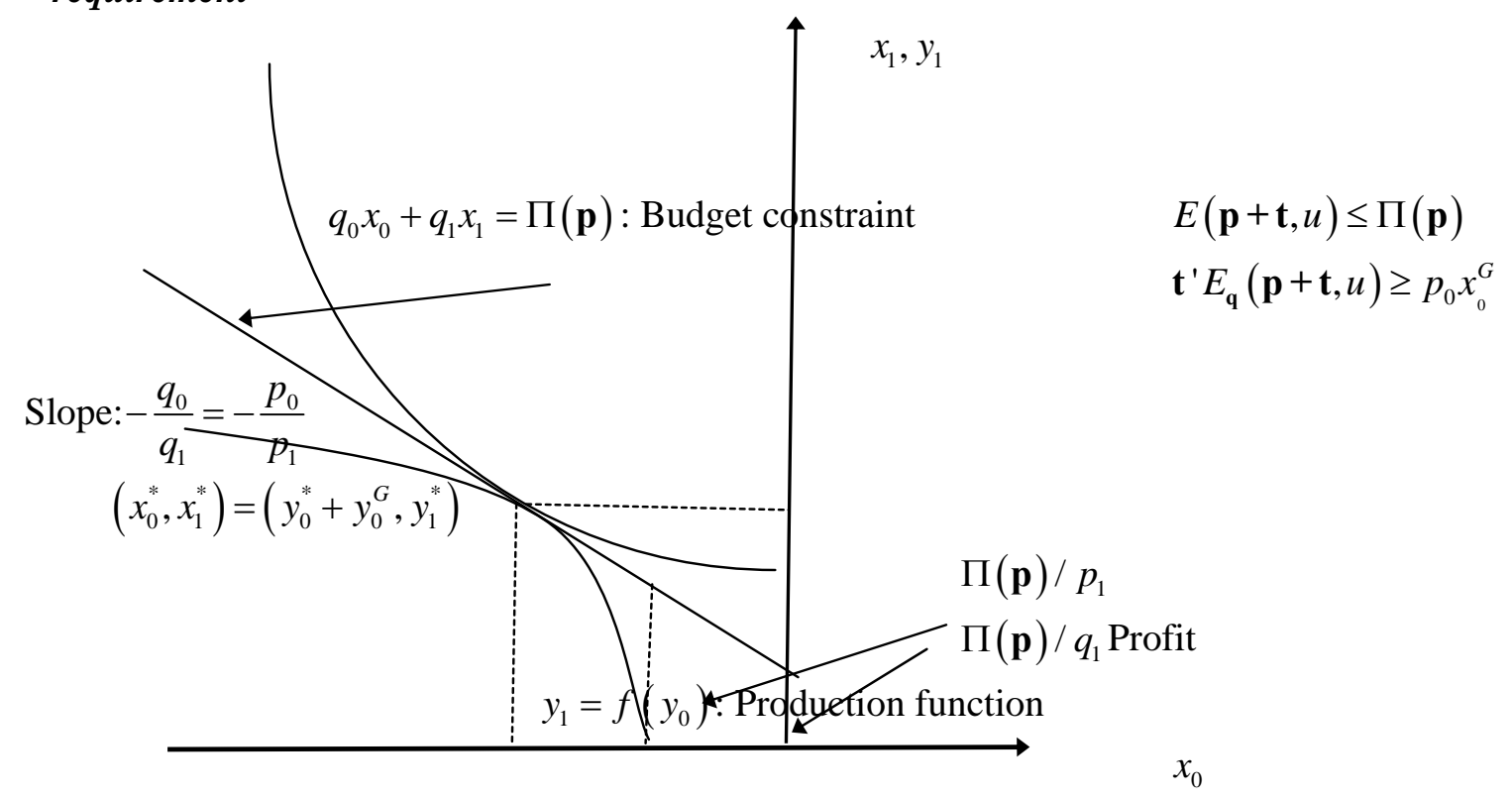

Figure 2b: Taxation of net purchases. Value of profit less than the government's requirement

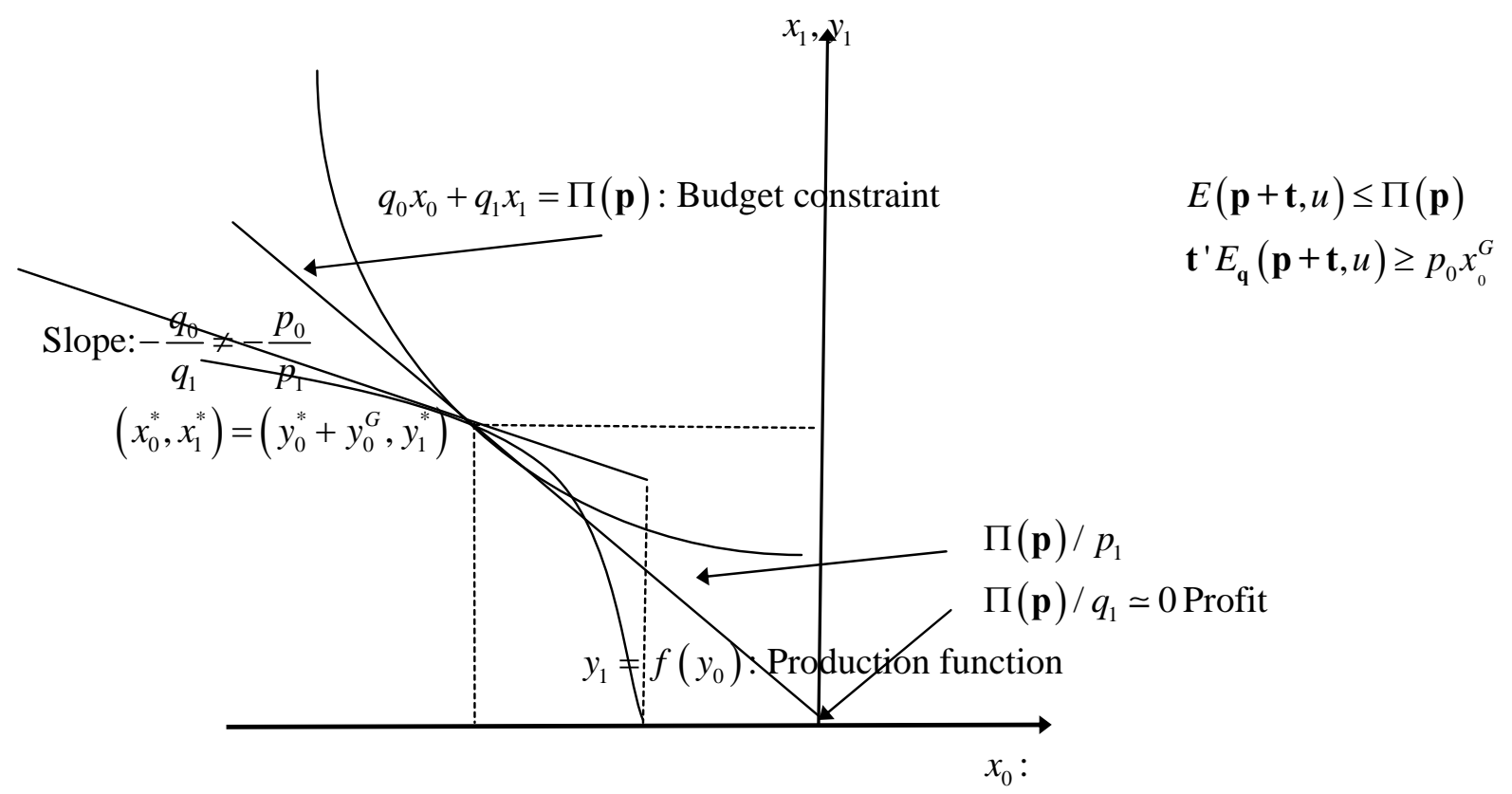




\section{The rules of normalisation and intuitive insight into what determines the optimal tax system}

By the homogeneity of degree zero of compensate demand and the homogeneity of the profit function of degree 1 , in all the three cases considered multiplying consumer prices, $\mathbf{q}$, and producer prices, $\mathbf{p}$, by the same constant, leaves the equilibrium conditions satisfied. Multiplying only $\mathbf{q}$ or $\mathbf{p}$ by a constant, the equilibrium conditions in Case 1 remain unaffected, but in Case 2 and 3 the value of the endowment and the value of the profit to the household, respectively, is affected. By the same type of proof as in Munk (1978) this leads to the following extension of Proposition 1 in that article.

Proposition 1: In tax models at least one price (either a producer price or a consumer price) must be fixed in order for there to be a unique solution to the maximisation problem. However, if taxation is based on net trade (rather than consumption), and if

a) $100 \%$ tax is imposed on profit, or

b) there are constant returns to scale, then one consumer price and at least one producer price must be fixed.

It follows from Proposition 1 that in the case of taxation based on net trade, when the household receives no profit income, one commodity may be assumed untaxed as a matter of normalisation, as is customary in optimal tax models. However, it is not the case that one commodity must be assumed untaxed to have a unique solution. A totally adequate normalisation rule is to assume that the tax on one commodity, say labour, is fixed at some value other than 0 .

Having established the proper rules of normalisation, it is easy by similar reasoning, without recourse to the mathematical theory of constrained maximisation, to establish the following proposition concerning the solutions to the government's problem of maximising social welfare under alternative sets of assumptions (cf. Munk 1978).

Proposition 2: When taxation

a) is based on net trade and there is no profit, then an optimal solution must involve distortion of consumer prices relative to consumer prices and thus always be second best;

b) is based on consumption the first best solution can always be established by a proportional tax structure $\frac{p_{i}+t_{i}}{p_{i}}=T, i \in F C$;

c) is based on net trade and profit income $I>G$, then the first best solution can be established by a proportional tax structure $\frac{p_{i}+t_{i}}{p_{i}}=T, i \in F C$;

d) is based on net trade and profit income $I<G$, then only a second best solution can be established and involves $\frac{p_{i}+t_{i}}{p_{i}} \approx \infty, i \in F C$.

Figure 1 and 2 illustrate this insight. Figure 1 illustrates that a first best solution is always possible in Case 2, but never in Case 1. Figure 2 illustrates that whether a first best solution 
is possible in Case 3 depend on the size of the profit relative to the value of the government's revenue requirement.

Since without loss of generality we in Case 1 can assume that $p_{0}=q_{0}$, adding this constraint to the governments problem in Case 2, results in the same optimal solution as in Case 1. This provides a good starting point for identifying what determines desirable directions of tax reform in Case 1 (the standard case considered in the theory of optimal taxation). Adding $p_{0}=q_{0}$ in Case 2 not only makes it impossible to achieve the first best solution, but it also clearly involves a substitution away from the consumption of produced commodities towards the consumption of leisure, and hence a discouragement of the supply of labour compared with the first best solution. In other words the distortion created by having to raise government revenue by distortionary taxes rather than by lump sum taxation, is thus basically that the supply of labour to the market is discouraged; (compare Figure 1a with Figure 1b).

The changes in prices from the first best allocation where the consumption of all commodities including leisure are taxed at the same rate to "a proportional tax system" (where only the consumption of the produced commodities are taxed at the same rate or where only the supply of labour is taxed), clearly makes the consumption of leisure more attractive compared with the consumption of all other commodities taken together. Such a price change will therefore - compared with the first best allocation - increase the household's consumption of leisure. However, it is in general possible, while keeping the government's revenue constant, to reduce this distortion by increasing the tax rates on the commodities which are highly complementary to leisure and reducing those on commodities which are less so. This suggests that starting from a proportional tax system, increasing tax rates on those commodities which are highly complementary with leisure, and decreasing them for those which are less complementary, will increase social welfare.

However, it is also clear that doing so creates another distortion. The marginal rates of substitution in consumption between produced commodities become different form the marginal rates of transformation in production. As the supply of labour is increased, the marginal costs in terms of welfare of this distortion will increase. This suggests that the optimal tax system is achieved where the marginal gain in terms of encouragement of the supply of labour corresponds to the marginal loss in terms of distortion of the pattern of consumption of produced commodities. In other words, the optimal tax system represents a compromise between two objectives:

1) the objective of encouraging the supply of labour to the market, $x_{0}$, (Objective 1), and

2) the objective of limiting the distortion of the pattern of consumption of produced commodities $x_{i}, i \in C$, (Objective 2).

In Section 4 and 6, respectively, we provide formal proofs of these conjectures about what constitute desirable tax reforms, and about what characterise optimal systems of taxation. 


\section{Reinterpretation of some analytical results}

The condition that the value of the expenditure function is equal to household income we have indicated in the three cases considered by (13), (16) and (19), respectively. Dixit (1975) writes $E(1, q, u)=Z-T+P$ as a generic condition for equilibrium covering all these three cases. In Dixit's notation, $P$ is untaxed profit, $T$ is a lump sum tax and $Z$ other income. Assuming that lump sum taxation is not available to the government, i.e. $T=0$, the equivalent expression in our notation, in Case 2, is $Z \equiv \omega_{0}$ and $E(1, q, u) \equiv M(\mathbf{q}, u)$, in Case 1 and $3, Z \equiv 0$ and $E(1, q, u) \equiv E(\mathbf{q}, u)$, and in Case 3, $P=\Pi(\mathbf{p})$. Dixit (1975, op. cit. p, 106) thus in all the three cases assumes that $p_{0}=q_{0}=1$. By doing so Dixit obscures the distinction between the behavioural assumption that the household use of the primary factor cannot be taxed, and the assumption that the supply of the primary factor to the market is untaxed. The former assumption constrains the set of feasible solutions, while the latter does not. This leads Dixit to misinterpret his analytical results. Dixit's analysis was in Dixit and Munk (1977) reinterpreted taking into account that in Case 3 labour cannot be assumed untaxed without loss of generality. The present paper reinterprets some of Dixit's results for Case 1 drawing insight that also in Case 2, which is in itself not a case of particular interest, that labour cannot be assumed untaxed without loss of generality.

Analysing the effect of a tax reform in Case 1 starting from a proportional tax system, $T_{i}=T, i \in C$, we adopt the same analytical approach as Dixit (1975, op. cit), but do not initially make any assumption about normalisation. Such a tax reform changes the equilibrium consumer price vector to $(\mathbf{q}+\mathrm{d} \mathbf{q})$, and the utility to $(u+\mathrm{d} u)$, leaving the government's revenue unchanged. For simplicity we assume a linear production structure such that producer prices may be assumed fixed. ${ }^{2}$

Taking total differentials of (13) and (14), we obtain

$$
\begin{aligned}
& \mathbf{E}_{\mathbf{q}} \mathrm{d} \mathbf{q}+\mathbf{E}_{u} \mathrm{~d} u=0 \\
& \mathbf{E}_{\mathbf{q}} \mathrm{d} \mathbf{q}+\mathbf{t}^{\prime} \mathbf{E}_{\mathbf{q q}} \mathrm{d} \mathbf{q}+\mathbf{t}^{\prime} \mathbf{E}_{\mathbf{q} u} \mathrm{~d} u=0
\end{aligned}
$$

Solving for $\mathrm{d} u$, using that $\mathbf{t}=\mathbf{q}-\mathbf{p}$, and that by homogeneity that $\mathbf{q}^{\prime} \mathbf{E}_{\mathbf{q u}}=\mathbf{E}_{u}$, we have

$$
\mathrm{d} u=\Phi \mathbf{t}^{\prime} \mathbf{E}_{\mathbf{q q}} \mathrm{d} \mathbf{q}
$$

where $\Phi=1 /\left(\mathbf{E}_{u}+\mathbf{p}^{\prime} \mathbf{E}_{\mathbf{q} u}\right)$. We assume that $\left(\mathbf{E}_{u}+\mathbf{p}^{\prime} \mathbf{E}_{\mathbf{q} u}\right)>0$ (see Dixit 1975, op. cit, p107 for justification).

\footnotetext{
${ }^{2}$ With variable producer price and in the presence of profit, if the profit is taxed at $100 \%$, one commodity may also be assumed untaxed without loss of generality. The optimal tax rules are the same as in the case of a linear production structure, but the analysis is complicated by producer prices being endogenous (see Munk and Dixit 1977 and Munk 1978).
} 
We now define $\mathbf{t}_{-0}$ and $\mathrm{d} \mathbf{q}_{-0}$ as equal to the corresponding vectors where the $0^{\text {th }}$ element has been removed, $\mathbf{E}_{\mathbf{q}_{-0} \mathbf{q}_{-0}}$ as equal to $\mathbf{E}_{\mathbf{q q}}$, where the $0^{\text {th }}$ row and the $0^{\text {th }}$ column has been removed, and $\mathbf{E}_{\mathbf{q}_{-0} 0}$ as equal to the first row of $\mathbf{E}_{\mathbf{q q}}$. Assuming that $\mathrm{d} q_{0}=0$ we have

$$
\mathbf{t}^{\prime} \mathbf{E}_{\mathbf{q q}}=t_{0} \mathbf{E}_{\mathbf{q}_{-0} 0} \mathrm{~d} \mathbf{q}_{-0}+\mathbf{t}_{-0} \cdot \mathbf{E}_{\mathbf{q}_{-0} \mathbf{q}_{-0}} \mathrm{~d} \mathbf{q}_{-0}
$$

If we assume that the initial tax system is proportional, i.e. that the supply to the market of the primary factor is taxed at a fixed rate, $t_{0}$ and $t_{i}=\frac{T-1}{T} q_{i}>0$ for $i \in \mathrm{C}$, then $\frac{p_{i}+t_{i}}{p_{i}}=T>1$. With reference to Proposition 1 , we fix $t_{0}<0$ as a matter of normalisation. We now consider a tax reform which changes consumer prices by $\mathrm{d}_{\mathbf{q}_{-0}}$. Substituting for $\mathbf{t}^{\prime} \mathbf{E}_{\mathbf{q q}}$ in (9) using (10) we have

$$
\mathrm{d} u=\Phi\left(t_{0} \mathbf{E}_{\mathbf{q}_{-0} 0} \mathrm{~d} \mathbf{q}_{-0}+\frac{T-1}{T} \mathbf{q}_{-0} \mathbf{E}_{\mathbf{q}_{-0} \mathbf{q}_{-0}} \mathrm{~d} \mathbf{q}_{-0}\right)
$$

Since by the homogeneity of degree zero of $\mathbf{E}_{\mathbf{q}_{-0}}$ in $\mathbf{q}, q_{0} \mathbf{E}_{\mathbf{q}_{-0} 0}+\mathbf{q}_{-0}{ }^{\prime} \mathbf{E}_{\mathbf{q}_{-0} \mathbf{q}_{-0}}=0$, and by the symmetry of demand derivatives, $\mathbf{E}_{\mathbf{q}_{-0} 0}=\mathbf{E}_{0 \mathbf{q}_{-0}}^{\prime}$

$$
\mathrm{d} u=-\Phi\left(t_{0}-\frac{T-1}{T} q_{0}\right) \mathbf{E}_{0 \mathbf{q}_{-0}}^{\prime} \mathrm{d} \mathbf{q}_{-0}
$$

Substituting in (27) by $\mathrm{d} x_{0}=q_{0} \mathbf{E}_{\mathbf{q}_{-0} 0}$, the change in the supply to the market of the primary factor (measured negatively), for $\mathbf{E}_{0 \mathbf{q}_{-0}} \mathrm{~d} \mathbf{q}_{-0}$, and exploiting the symmetry of the derivatives of compensated demand, we have

$$
\mathrm{d} u=\Phi\left(t_{0}-\frac{T-1}{T} q_{0}\right) \mathrm{d} x_{0}>0
$$

The following proposition provides the interpretation of this equation.

Proposition 3: In a competitive economy with constant producer prices and one primary factor, in an equilibrium with a proportional tax system in terms of the produced commodities, a small change in tax rates holding commodity tax revenue constant will increase welfare if the changes in tax rates result in an increase in the compensated supply of the primary factor.

A increase in the tax on commodity $j$ balanced by a decrease in the tax on a commodity $i$ changes the compensated supply of the primary factor by (see Dixit op. cit. p116)

$$
\begin{aligned}
& \mathrm{d} x_{0}=E_{0 i} d t_{i}+E_{0 j} d t_{j} \\
& \mathrm{~d} x_{0}=\alpha_{0} \sigma_{i 0} x_{i} d t_{i}+\alpha_{0} \sigma_{j 0} x_{j} d t_{j}
\end{aligned}
$$


where $\alpha_{i} \equiv q_{i} x_{i} / q_{0} \omega_{0}$ and where $\sigma_{k 0}, k=i, j$, are Allen (or Allen-Uzawa) elasticities of substitution.be defined as

$$
\sigma_{i j} \equiv \frac{M(\mathbf{q}, u) M_{i j}(\mathbf{q}, u)}{M_{i}(\mathbf{q}, u) M_{j}(\mathbf{q}, u)} \quad i, j \in F C
$$

where $M(\mathbf{q}, u)$ is the full income expenditure function.

For a tax reform to be welfare improving it follows from (22) that $x_{i} d t_{i}+x_{j} d t_{j}<0$ and thus that

$$
\mathrm{d} x_{0} \leq\left(\sigma_{j 0}-\sigma_{i 0}\right) \alpha_{0} x_{j} d t_{j}
$$

A welfare increasing tax reform, which balance an increase in the tax on commodity $j$ by a reduction in the tax on commodity, will thus, if $\sigma_{i 0}>\sigma_{j 0}$, increase the supply of the primary factor $\left(\mathrm{d} x_{0}<0\right)$. Combining this result with Proposition 3, we obtain (cf. The Corlett and Hague 1953 analysis reviewed below) the following proposition which confirms the first conjecture formulated in Section 4.

Proposition 4: In a competitive economy with constant producer prices and one primary factor, in an equilibrium with a proportional tax system, a small decrease in the tax on one commodity balanced by a increase of the tax of another commodity less complementary with the untaxed use of the primary factor than the first commodity, will increase welfare.

Dixit's Theorem $6^{3}$ follows from Proposition 4 when "the numeraire" is replaced by "the household's untaxed use of the primary factor". The theorem is not valid if any other commodity than the primary factor is chosen as untaxed numeraire. To see this, consider the case where in the initial equilibrium the tax system is proportional with $T_{0}<1, T=1$. In this case any of the produced commodities may be considered an untaxed numeraire, but the Dixit's theorem does not apply with that choice of numeraire. The theorem suggests that the degree of complementarity with the untaxed numeraire is important for what constitutes welfare improving directions of tax reform. The importance of the link to the untaxed numeraire is coincidental, attributable to the fact that Dixit has chosen as numeraire the commodity of which the household has an initial endowment, i.e. the primary factor.

Dixit's Theorem $7^{4}$ may similarly be reinterpreting by replacing "the numeraire" by "the untaxed use of the primary factor”.

\footnotetext{
${ }^{3}$ Dixit (1975, op cit)'s Theorem 6 says “In a competitive economy with constant producer prices and an initial equilibrium with equal proportional distortions, a small change in tax rates holding commodity tax revenue constant will increase welfare if all commodities whose prices and lowered are better substitutes for the numeraire that all those whose prices are raised"

${ }^{4}$ Dixit (1975, op cit)'s Theorem 7 says "Lowering the price of any one commodity towards its marginal cost will increase welfare if the commodity is complementary to all those with a greater proportional distortion and substitute for all other including the numeraire"
} 


\section{Adding structure to the representation of household preferences}

With the same motivation as Atkinson and Stern $(1980,1981)$ we now address the task of creating a framework which can be used for simulation studies to enhance intuition for the results presented above and to provide the basis for applied tax reform analysis. An essential requirement for such a framework is that it, in contrast to standard functional forms, does not impose separability between consumption of produced commodities and leisure.

\subsection{Household preferences with the explicit representation of the use of time}

In order not to impose the unrealistic assumptions of additive separable utility functions I have followed the same path as earlier taken by Atkinson and Stern $(1980,1981)$ of incorporating household production in the household's utility function in the spirit of Becker's theory of household production. In applied work I have adopted a utility function, which allows the interaction between the consumption of produced commodities and leisure to differ between produced commodities (see Munk 1998, 1999, 2004 and 2008). I have used a utility function with an explicit representation of the use of time,

$$
U\left(c_{0}^{0}, C_{1}\left(x_{1}, c_{0}^{1}\right), C_{2}\left(x_{2}, c_{0}^{2}\right), \ldots, C_{N}\left(x_{N}, c_{0}^{N}\right)\right)
$$

where $c_{0}^{0}=\omega_{0}-\sum_{i \in \mathrm{C}} c_{0}^{i}+x_{0}$ is "pure leisure" ${ }^{5}$. For each composite good, $C_{i}$, the preference for the amount purchased of the commodity, $x_{i}$, and the time used for its consumption, $c_{0}^{i}$, is expressed by a concave functions $C_{i}=C_{i}\left(x_{i}, c_{0}^{i}\right), i \in C$. These functions may be interpreted as representing either household production or consumption activities ${ }^{6}$. "Leisure" or "nonmarket use of time" is therefore $c_{0}=\omega_{0}+x_{0}=\sum_{i \in \mathrm{C}} c_{0}^{i}+c_{0}^{0} . U\left(c_{0}^{0}, C_{1}, C_{2}, \ldots, C_{N}\right)$ I have assumed to be strictly quasi-concave.

\footnotetext{
5 "Pure leisure" is thus defined as the amount of time spent on activities, which are not associated with the consumption of purchased commodities or the supply of labour to the market. We are not here going to be drawn into a philosophical discussion of whether "pure leisure" exits from an ontological point of view. Any scientific theory has to be developed in such a way that it can be applied to data that are available, or at least can potentially be made available, and not by trying to represent the world as it "really" is. For empirical purposes we interpret "pure leisure" as non-market use of time which cannot be related to the consumption of any specific commodity, for example as time used for relaxation in one's home which typically involves the use of many durable commodities at the same time. The motivation of the definition is thus pragmatic, to improve the quality of work otherwise constrained by the unrealistic assumption of separability between consumption of produced commodities and the consumption of nonmarket use of time.

${ }^{6}$ The aggregation functions, $C_{i}\left(x_{i}, C_{0}^{i}\right), i \in C$, may be interpreted as household production functions, or as just constraining household preferences. In the first case, a composite commodity, $C_{i}$, is a physical entity resulting from the combinations of a purchased commodity and time, as in the case of food prepared in the home; in the second case, the composite commodity is just a theoretical construct helping to represent the household's preferences, as in the case of childcare where alternative combinations of non-marketed time and the purchase of a marketed commodity can satisfy the same well-defined need. The one interpretation may be used for one application and the other for another, but it does not matter for the formal analysis undertaken here.
} 
The assumption that the household maximises utility subject to its budget constraint may, using the expenditure function approach, be expressed as

$$
\begin{aligned}
& E\left(q_{0}, q_{1}, . ., q_{\mathrm{N}}, u\right) \equiv \operatorname{Min}_{c_{0}^{i}, i \in F C ; x_{i}, i \in F C} q_{0} x_{0}+\sum_{i \in \mathrm{C}} q_{i} x_{i} \text { s.t. } \\
& u=U\left(\omega_{0}+x_{0}-\sum_{i \in \mathrm{C}} c_{0}^{i}, C_{1}\left(x_{1}, c_{0}^{1}\right), C_{2}\left(x_{2}, c_{0}^{2}\right), . ., C_{\mathrm{N}}\left(x_{\mathrm{N}}, c_{0}^{\mathrm{N}}\right)\right)
\end{aligned}
$$

where $E\left(q_{0}, q_{1}, . ., q_{\mathrm{N}}, u\right)$ is an expenditure function with standard properties.

Assuming that the functions $C_{i}=C_{i}\left(x_{i}, c_{0}^{i}\right), i \in C$, are homogenous of degree 1 , we may define prices for the composite commodities as

$$
Q_{i}=Q_{i}\left(q_{0}, q_{i}\right) \equiv\left(\operatorname{Min}_{c_{0}^{i}, x_{i}} q_{0} c_{0}^{i}+q_{i} x_{i} \text { s.t. } C_{i}\left(c_{0}^{i}, x_{i}\right)\right) / C_{i}
$$

and

$$
\tilde{E}\left(q_{0}, Q_{1}, Q_{2}, . ., Q_{N}, u\right) \equiv \operatorname{Min}_{c_{0}, ; C_{i}, i \in F C} q_{0} c_{0}+\sum_{i \in \mathrm{C}} Q_{i} C_{i} \text { s.t. } u=U\left(c_{0}, C_{1}, \ldots, C_{\mathrm{N}}\right)
$$

The function $\tilde{E}\left(q_{0}, Q_{1}\left(q_{0}, q_{1}\right), Q_{2}\left(q_{0}, q_{2}\right), \ldots, Q_{N}\left(q_{0}, q_{\mathrm{N}}\right), u\right)-q_{0} \omega_{0}$ is $\quad$ an $\quad$ expenditure function with standard properties which represent the same preferences as $E\left(q_{0}, q_{1}, \ldots, q_{\mathrm{N}}, u\right)$. This follows from $\tilde{E}\left(q_{0}, Q_{1}, Q_{2}, \ldots, Q_{N}, u\right)$, and $Q_{i}\left(q_{0}, q_{i}\right) C_{i}$, $i \in \mathrm{C}$ being expenditure functions with standard properties ${ }^{7}$. This is an essential point; it implies that the corresponding demand system can be analysed using standard demand theory, and that the insight from standard tax reform analysis can be applied directly. That we can apply standard results is not only of considerable analytical convenience, but also facilitates the interpretation of results as was pointed out by Atkinson and Stern (1980) ${ }^{8}$. But in order to exploit these advantages, it is naturally important, as emphasised in Munk (2001), to make a correct mapping of the variables from the utility function with explicit representation of the use of time to the utility function in its standard form, Let us to clarify this, write $G^{i}\left(q_{0}, q_{1}, C_{i}\right)$ for the cost function associated with $C_{i}=C_{i}\left(x_{i}, c_{0}^{i}\right)$ as in Munk (1980). The conditions for maximisation of (shadow) profit of household production may then be expressed as

$$
\begin{aligned}
& x_{i}=G_{i}^{i}\left(q_{0}, q_{i}, C_{i}\right), i \in C \\
& c_{0}^{i}=G_{0}^{i}\left(q_{0}, q_{i}, C_{i}\right), i \in C \\
& Q_{i}=G_{C_{i}}^{i}\left(q_{0}, q_{1}, C_{i}\right), i \in C
\end{aligned}
$$

\footnotetext{
${ }^{7}$ See also see Pollak and Wachter (1975)

${ }^{8}$ Atkinson and Stern (1980) write: In the formal sense [a model incorporating home production] is no different, and we can apply the standard theory of demand, a fact which is worth emphasising in view of the claims sometimes made to the contrary. That we can apply standard results is a considerable analytical convenience, and allows us to see more clearly how the interpretation of the results differs [when incorporating home production]
} 
where $Q_{i}=G_{C_{i}}^{i}\left(q_{0}, q_{i}, C_{i}\right) \equiv \frac{\partial G^{i}}{\partial C_{i}}, G_{0}^{i}\left(q_{0}, q_{i}, C_{i}\right) \equiv \frac{\partial G^{i}}{\partial q_{0}}$ and $G_{i}^{i}\left(q_{0}, q_{i}, C_{i}\right) \equiv \frac{\partial G^{i}}{\partial q_{i}}$.

In the case of a standard utility function the household's preferences are defined on net trade, $x_{0}, x_{1}, . ., x_{\mathrm{N}}$. In the case of a utility function with the explicit representation of the use of time, the household's preferences are defined on pure leisure, $c_{0}^{0}$, and the consumption of composite commodities, $C_{1}, . ., C_{N}$. What we have shown is that the behaviour implied by the utility function with explicit representation of the use of time, $U\left(c_{0}^{0}, C_{1}\left(x_{1}, c_{0}^{1}\right), C_{2}\left(x_{2}, c_{0}^{2}\right), \ldots, C_{\mathrm{N}}\left(x_{\mathrm{N}}, c_{0}^{\mathrm{N}}\right)\right)$, corresponds to that of an utility function with standard properties, $u\left(x_{0}, x_{1}, . ., x_{\mathrm{N}}\right)$, defined on net trade.

The net trade vector $\mathbf{x} \equiv\left(x_{0}, x_{1}, ., x_{\mathrm{N}}\right) \equiv \boldsymbol{\omega}-\mathbf{c}$ indicates the household's interaction with the rest of the world, which in optimal tax theory is the only aspect of household behaviour, which is assumed to be observable by the government. The use of utility functions with the explicit representation of the use of time provides more power to the explanation of changes in $\mathbf{x}$ in response to price changes than the use of standard utility functions, but remains, as we have seen, a special case of the general formulation. It is thus inconceivable that optimal tax results obtained for the general case should not be applicable to cases where household preferences are represented by utility functions with the explicit representation of the use of time.

We can thus express the household maximisation problem in two ways which are entirely equivalent, as was pointed out by Atkinson and Stern (1980, 1981). We can incorporate household production in the household utility function

$$
\begin{aligned}
& \operatorname{Max}_{x_{i}, i=0,1,2,3 ; c_{0}^{i}, i=1,2,3} U\left(C_{1}\left(x_{1}, c_{0}^{1}\right), C_{2}\left(x_{2}, c_{0}^{2}\right), C_{3}\left(x_{3}, c_{0}^{3}\right),\left(\omega_{0}^{h}-\sum_{i \in(1,2,3)} c_{0}^{i . h}+x_{0}\right)\right) \\
& \text { st. } \sum_{i \in C} q_{i} x_{i}+q_{0} x_{0}=0
\end{aligned}
$$

or we can add the condition for profit maximisation in the household sector to the household maximisation problem,

$$
\begin{aligned}
& \operatorname{Max}_{C_{i}, i \in C ; c_{0}^{0}} U\left(c_{0}^{0}, C_{1}, \ldots, C_{N}\right) \text { s.t. } \\
& \sum_{i \in C} Q_{i} C_{i}+q_{0} c_{0}^{0}=q_{0} \omega_{0}+\sum_{i \in C} \Pi^{i}\left(q_{0}, q_{1}, C_{i}\right)
\end{aligned}
$$

where

$$
x_{0}=c_{0}^{0}+\sum_{i \in C} c_{0}^{i}-\omega_{0}
$$




$$
\begin{aligned}
& x_{i}=c_{i}\left(q_{0}, q_{i}, C_{i}\right), i \in C \\
& c_{0}^{i}=c_{0}^{i}\left(q_{0}, q_{i}, C_{i}\right), i \in C \\
& Q_{i}=\Pi_{i}^{i}\left(q_{0}, q_{i}, C_{i}\right), i \in C \\
& \Pi^{i}\left(q_{0}, q_{1}, C_{i}\right) \equiv Q_{i} C_{i}-G^{i}\left(q_{0}, q_{1}, C_{i}\right), i \in C
\end{aligned}
$$

As long as the sub-utility functions representing household production, $C_{i}=C_{i}\left(x_{i}, c_{0}^{i}\right), i \in C$, are well behaved concave functions, household production may be interpreted as a special case of a utility function $u\left(x_{0}, x_{1}, \ldots, x_{N}\right)$ satisfying standard conditions of quasi-concavity and monotonicity. The explicit representation of household production thus does not compromise the application of general theorems of consumer theory and the theory of optimal taxation. This is one of the great advantages of incorporating the representation of household consumption in the utility function. The optimal solution to the household maximisation problem in terms of $u\left(x_{0}, x_{1}, \ldots, x_{N}\right)$ thus remains the same whether it is formulated as (37) or (38) As has been stated in Munk (2001), the suggestion by Kleven, Richter and Sørensen (2000), quoted by Boadway and Gahvari (2006) and Sørensen (2007), that household consumption provides a counter example to the Diamond and Mirrlees Production Efficiency Theorem is therefore misguided. It seems based on a misunderstanding of both the role of the interaction between the consumption of produced commodities and the "consumption of leisure" which in optimal tax models in the Diamond-Mirrlees tradition should be understood as the household's untaxed use of labour, and not as the term "leisure" may be used in common language. In particular it is worth noticing that the Diamond and Mirrlees Production Efficiency Theorem does apply in the presence of untaxed profit in the informal sector, as stated in Munk (2001), and as formally spelt out here. Diversion from production efficiency is desirable in the case of untaxed profit in the formal sector only if restrictions are imposed on the set of commodity taxes; if such restrictions are imposed the rationale for taking the characteristics of the production structure into account is that it allows the value of the profit income accruing to the household to be reduced (see Munk 1978, 1980). As considering the household's maximisation problem as expressed in (38) demonstrates, the value of the informal sector profit is invariant to a proportional increase in consumer prices. Representing household production as a separate untaxed production sector therefore does change neither the optimal tax structure nor the rational for why commodities should be taxed at different rates according to their complementary with the untaxed use of the primary factor. This insight follows from the first formulation of government's problem of finding an optimal solution, (37). However, it is may be more clearly seen from the second formulation, (38). As the household budget constraint is unaffected by a proportional increase in all prices, we can assume labour untaxed as is customary in optimal tax models without loss of generality. It is instructive, to contrast the case of untaxed profit in the household sector with the case of untaxed profit in the formal production sector considered in Munk $(1978,1980)$.

\section{Characterisation of the optimal tax structure}

We now address the question of how to provide a formal characterisation of the optimal tax system in order to provide a formal proof of the second conjecture formulated in Section 4. 


\subsection{The standard analysis}

The government's maximisation problem may be represented by

$$
\begin{aligned}
& \underset{\left\{t_{i}, i \in \mathrm{FC}\right\}, u}{\operatorname{Max}} u \text { s. t. } \\
& E(\overline{\mathbf{p}}+\mathbf{t}, u)=-L \text { and } \\
& \sum_{i \in \mathrm{FC}} t_{i} E_{i}(\overline{\mathbf{p}}+\mathbf{t}, u)+L-G=0
\end{aligned}
$$

where $L=0$.

The corresponding Lagrangian expression may therefore be written as

$$
\mathrm{L}=u+\mu(-L-E(\overline{\mathbf{p}}+\mathbf{t}, u))+\lambda\left(\sum_{\mathrm{i} \in \mathrm{FC}} t_{\mathrm{i}} E_{\mathrm{i}}(\overline{\mathbf{p}}+\mathbf{t}, u)+L-G\right)
$$

By properties of Lagrangian multipliers, the net marginal social value of income for the household, is the increase in social welfare if the income of the household were increased by one unit from outside the economy (cf. Diamond 1975) and $\lambda$, the marginal social opportunity cost price of government funds, if it is the government which receives the income transfer.

The first order conditions for an optimal solution with respect to $u, L$ and $\mathbf{q} \equiv\left(q_{0}, q_{1}, \ldots, q_{\mathrm{N}}\right)$, respectively, are

$$
\begin{aligned}
& \frac{\partial \mathrm{L}}{\partial u}=1-\mu E_{u}+\lambda \sum_{i=0}^{N} t_{i} E_{i u}=0 \\
& \frac{\partial \mathrm{L}}{\partial L}=-\mu+\lambda=0 \\
& \frac{\partial \mathrm{L}}{\partial q_{k}}=-\mu x_{k}+\lambda\left(\sum_{i \in F C} t_{i} E_{i k}+x_{k}\right)=0
\end{aligned}
$$

where, $E_{\mathrm{ij}} \equiv \frac{\partial^{2} E}{\partial q_{i} \partial q_{j}}=\frac{\partial x_{i}}{\partial q_{j}}, E_{\mathrm{u}} \equiv \frac{\partial E}{\partial u}=1 / \frac{\partial V}{\partial I}$, and $E_{\mathrm{iu}} \equiv \frac{\partial^{2} E}{\partial q_{i} \partial u}=\frac{\partial x}{\partial I} / \frac{\partial V}{\partial I}$.

Notice that if lump sum tax were feasible, then the two other first order conditions would be satisfied for $\mathbf{t}=0$, i.e. only the lump sum tax instrument would be used and the optimal solution would be first best.

We define the social value of income as $\beta \equiv \frac{\partial V(\mathbf{q}, I)}{\partial I}=1 / E_{u}$. From (41) we then have that the net social value of income is

$$
\mu=\beta+\lambda \sum_{i=0}^{N} t_{i} \frac{\partial x_{i}(\mathbf{q}, I)}{\partial I}
$$

and from (43) that

$$
\sum_{i=0}^{N} t_{i} E_{i k}(\mathbf{q}, u)=-\theta x_{k}
$$


where $\theta \equiv(\lambda-\mu) / \lambda$.

Since $\left\{E_{i k}(\mathbf{q}, u), i, j=0,1, . ., \mathrm{N}\right\}$ is negative definite

$$
\sum_{k=0}^{N} \sum_{i=0}^{N} t_{i} t_{k} E_{i k}(\mathbf{q}, u)=-\theta \mathbf{t x}<0
$$

Therefore, if $\mathbf{t x}>0$ then

$$
\lambda>\mu=\beta+\lambda \sum_{i=0}^{N} t_{i} \frac{\partial x_{i}(\mathbf{q}, I)}{\partial I}
$$

i.e. if the tax revenue is positive then the social value of an increase in government revenue, $\lambda$, is larger than the net social marginal utility of income, $\mu$. Notice that whether $\lambda>\beta$ depends on normalisation. ${ }^{9}$

\subsection{The optimal tax system in the case of two produced commodities}

Choosing the primary factor, commodity 0 , as untaxed numeraire the first order conditions for an optimal tax structure (45) may in an economy with only two produced commodities in matrix notation be written as

$$
\left[\begin{array}{ll}
E_{11} & E_{12} \\
E_{21} & E_{22}
\end{array}\right]\left[\begin{array}{l}
t_{1} \\
t_{2}
\end{array}\right]=\left[\begin{array}{l}
-\theta x_{1} \\
-\theta x_{2}
\end{array}\right]
$$

By the application of Kramer's rule and using that $E_{j}(\mathbf{q}, u)$ is homogeneous of degree 0 , we have

$$
\frac{t_{1} / q_{1}}{t_{2} / q_{2}}=\frac{-\varepsilon_{11}-\varepsilon_{22}-\varepsilon_{10}}{-\varepsilon_{11}-\varepsilon_{22}-\varepsilon_{20}}
$$

Since and $\varepsilon_{j 0}=\alpha_{0} \sigma_{j 0}$, where $\alpha_{i}=\frac{q_{i} C_{i}}{q_{0} \omega_{0}}$, we may rewrite (49) as

\footnotetext{
${ }^{9}$ Contrary to the impression which may be obtained from some authors, the sign of $\frac{\lambda-\beta}{\lambda}$ is not always greater than zero. The value of $\frac{\lambda-\beta}{\lambda}$ depends on the rule of normalisation adopted. If $t_{0}=0$ then $\sum_{i=0}^{N} t_{i} \frac{\partial x_{i}(\mathbf{q}, I)}{\partial I}>0$, but if, say, $t_{1}=0$, then in general $\sum_{i=0}^{N} t_{i} \frac{\partial x_{i}(\mathbf{q}, I)}{\partial I}<0$.
} 


$$
\frac{t_{1} / q_{1}}{t_{2} / q_{2}}=\frac{\left(-\varepsilon_{11}-\varepsilon_{22}\right)-\alpha_{0} \sigma_{10}}{\left(-\varepsilon_{11}-\varepsilon_{22}\right)-\alpha_{0} \sigma_{20}}
$$

As own compensated price elasticities, $\varepsilon_{i i}$, are always negative,

$$
\sigma_{10}<\sigma_{20} \text { imply } t_{1} / q_{1}>t_{2} / q_{2}
$$

In order to facilitate the interpretation of (50) we define the Indicator of the objective of maintaining the first-best pattern of consumption of produced commodities (Objective 1) as

$$
\begin{aligned}
& I_{1} \equiv-\varepsilon_{11}-\varepsilon_{22} \\
& I_{1} \equiv\left(\alpha_{1}+\alpha_{2}\right) \sigma_{12}
\end{aligned}
$$

and the Indicator of the objective of increasing the supply of labour (Objective 2) as

$$
\begin{aligned}
& I_{2} \equiv \varepsilon_{10}-\varepsilon_{20} \\
& I_{2} \equiv \alpha_{0}\left(\sigma_{10}-\sigma_{20}\right)
\end{aligned}
$$

The optimal price formula (50), thus imply the following:

- Which commodity will be taxed at the highest rate, depends entirely on the sign of $\varepsilon_{10}-\varepsilon_{20}$

- For a given value of $-\varepsilon_{11}-\varepsilon_{22}$, the difference is the greater, the greater the numerical value of $\varepsilon_{10}-\varepsilon_{20}$

- For given values of $\varepsilon_{10}$ and $\varepsilon_{20}$, the difference is the smaller the greater is $-\varepsilon_{11}-\varepsilon_{22}$.

The larger is $I_{1}$, i.e. the larger is $\sigma_{12}$ the larger are the distortionary costs of differentiating the tax rates between the produced commodities, and for given values of $\varepsilon_{10}$ and $\varepsilon_{20}$ the difference in tax rates are smaller the greater is $I_{1}$, in other words the greater the cross price elasticity between the two produced commodities.

The larger $I_{2}$ is numerically, i.e. the larger is the difference in complementary $\left(\sigma_{10}-\sigma_{20}\right)$ and the larger the share of pure leisure, $\alpha_{0}$, the larger are the gains of differentiating the percentage tax rates between the produced commodities.

Which commodity will be taxed at the highest rate depends entirely on the sign of $I_{2}$ and, for given value of $I_{1}$, the difference is the greater the greater the numerical value of $I_{2}$.

\subsection{The optimal tax system in the case of many produced commodities}


The result of the Corlett and Hague analysis cannot formally be generalised to an economy with more than two produced commodities. This has lead to attempt to gain insight inter what constitutes the optimal tax structure by making restrictive assumptions.

The necessary conditions for an optimal tax system may be expressed as

$$
\sum_{i \in \mathrm{FC}} \frac{t_{i}}{q_{i}} \varepsilon_{k i}=-\theta
$$

where $\varepsilon_{i k} \equiv E_{i k} / \frac{x_{i}}{q_{k}}, i, k \in \mathrm{FC}$ are compensated demand elasticities and where $\theta \equiv \frac{\lambda-\mu}{\lambda}>0$. When $i=k$, rewriting (51) we get

$$
\frac{t_{i}}{q_{i}}=\left[\theta+a_{i}\right] 1 /-\varepsilon_{i i}
$$

where $a_{i}=\frac{\sum_{j \neq i=0}^{N} t_{j} E_{j i}(\mathbf{q}, u)}{E_{i}(\mathbf{q}, u)}$.

Therefore in the case where a utility function takes the form $u\left(\mathbf{x}^{\mathbf{h}}\right)=\sum_{i=1}^{N} u_{i}\left(x_{i}\right)+a x_{0}$, and where the expenditure function is therefore also additively separable (cf. Atkinson and Stiglitz 1980), the compensated cross price effects are zero. Assuming labour untaxed as a matter of normalisation, the optimal tax formula (51) reduces to the so-called inverse elasticity formula

$$
\frac{t_{i}}{q_{i}}=\theta 1 /-\varepsilon_{i i}
$$

However, since in this case $\varepsilon_{i 0}=-\varepsilon_{i i}$ we also have

$$
\frac{t_{i}}{q_{i}}=\theta 1 / \varepsilon_{i 0}
$$

Therefore taxing commodities with numerically small own price elasticities at relative high rates corresponds to taxing commodities that are highly complementary with leisure at high rates. The optimal tax system may therefore alternatively be seen as encouraging the labour supply compared to a proportional tax system based on the produced commodities by having higher taxes on commodities which are complementary with leisure, i.e. where $\varepsilon_{i 0}$ is small. The question is indeed if the inverse elasticity rule is not more misleading than enlightening as it only applies in the very special case where there is no conflict between the two in general competing objectives which determine the optimal tax system. ${ }^{10}$

\footnotetext{
${ }^{10}$ Furthermore, as is not always emphasised, the validity of the inverse elasticity rule requires that the income elasticity of all produced commodities are zero, or in other words that any increase in lump-sum income is used only to increase the consumption of leisure; an implication which is blatantly in contradiction all empirical evidence.
} 


\subsection{Derivation of optimal tax formula using the distance function}

It is in fact possible to characterise the optimal tax system in the case of many commodities as a trade-off between the two objectives identified in Section 3, however this requires the use of another concept of complementarity between consumption and leisure than employed in the Corlett and Hague analysis. We demonstrate this with reference to Deaton (1981b)'s much neglected analysis of optimal commodity taxation using the distance function.

The concept of complementarity may be defined based on the Allen elasticity of substitution, $\sigma_{i j}$, as used in the Corlett and Hague analysis, or based on the less well-known Antonelli elasticity of complementarity defined as

$$
\rho_{i j} \equiv \frac{D(\mathbf{c}, u) D_{i j}(\mathbf{c}, u)}{D_{i}(\mathbf{c}, u) D_{j}(\mathbf{c}, u)} \quad i, j \in F C
$$

where $D(\mathbf{c}, u)$ is the distance function (cf. Deaton 1981b) ${ }^{11}$.

Definition 1: Two commodities $i$ and $j$ are net $p$-complements (substitutes) for a given level of utility if an increase in the price of the $j^{\text {th }}$ commodity increases (decreases) the quantity consumed of the $i^{\text {th }}$ commodity (keeping the prices of all other commodities constant), i.e. if $\sigma_{i j} \geq 0(<0)(i \neq j)$.

Definition 2: Two commodities $i$ and $j$ are net q-complements (substitutes) for a given level of utility, if an increase in the consumption of the $j^{\text {th }}$ commodity increases (decreases) the marginal valuation of the $i^{\text {th }}$ commodity keeping the consumption of all other commodities constant, i.e. if $\rho_{i j} \geq 0(<0)(i \neq j)$.

The two concepts are linked since the distance function may be defined from the full income function. Let $\tilde{\mathbf{q}}$ be the vector of normalised commodity prices whose elements are $\tilde{q}_{i}=q_{i} / M$, $i=0, \ldots, \mathrm{N}$, where $M$ is full income. By the homogeneity of degree 1 of $M(\mathbf{q}, u)$ we have

$$
M(\tilde{\mathbf{q}}, u)=M M(\mathbf{q}, u)
$$

and thus

$$
\left\{\tilde{M}_{i j}\right\} \equiv\left\{\frac{\partial M_{i}(\tilde{\mathbf{q}}, u)}{\partial \tilde{q}_{j}}\right\}=1 / M\left\{M_{i j}\right\}
$$

The distance function may thus be defined as

$$
D(\mathbf{c}, u) \equiv \min _{\tilde{\mathbf{q}}}\{\tilde{\mathbf{q}} \mathbf{c} \text { s.t. } M(\tilde{\mathbf{q}}, u) \geq 1\}
$$

\footnotetext{
11 The distance function gives the maximum amount by which the consumption vector must be deflated or inflated to reach the indifference curve associated with $u$. The distance function is increasing, linear homogenous, and concave with respect to $\mathbf{x}$, and decreasing in $u$.
} 
Application of Shepard's lemma to the distance function yields the system of compensated inverse demand functions, $a_{i}(\mathbf{c}, u), i \in F C$

$$
\tilde{q}_{i}=\frac{\partial D(\mathbf{c}, u)}{\partial x_{i}} \equiv a_{i}(\mathbf{c}, u) \quad i \in F C
$$

Inverse demands measure the marginal evaluation of the consumption of commodities by the household. The linear homogeneity of the distance function implies that $D_{i}(\mathbf{c}, u) \equiv a_{i}(\mathbf{c}, u)$ is homogenous of degree zero in $\mathbf{x}$, and its concavity implies that the matrix $\left\{D_{i j}\right\} \equiv\left\{\frac{\partial a_{i}(\mathbf{c}, u)}{\partial c_{j}}\right\}$ is negative definite and symmetric. The inverse demand functions thus possess similar properties as the ordinary compensated demand functions $M_{i}(\mathbf{q}, u), i \in F C$.

The necessary conditions for an optimal tax structure,(45), may in matrix notation be written as

$$
\mathbf{E}_{\mathrm{qq}} \mathbf{t}=\mathbf{b}
$$

where

$$
\mathbf{E}_{\mathbf{q q}} \equiv\left[\begin{array}{ccc}
E_{00} & \cdot & E_{0 \mathrm{~N}} \\
\cdot & \cdot & \cdot \\
E_{\mathrm{N} 0} & \cdot & E_{\mathrm{NN}}
\end{array}\right], \mathbf{t} \equiv\left[\begin{array}{c}
t_{0} \\
\cdot \\
t_{\mathrm{N}}
\end{array}\right] \text { and } \mathbf{b} \equiv\left[\begin{array}{c}
-\theta x_{0} \\
\cdot \\
-\theta x_{N}
\end{array}\right] \text {, }
$$

As $\mathbf{E}_{\mathbf{q}}=\mathbf{c}-\boldsymbol{\omega}$, (59) may be rewritten as

$$
\mathbf{E}_{\mathbf{q q}} \mathbf{t}=-\theta(\mathbf{c}-\boldsymbol{\omega})
$$

Pre-multiplying by $\mathbf{D}_{\mathbf{q q}}$ and using that $\mathbf{M}_{\mathbf{q q}}=\mathbf{E}_{\mathbf{q q}}$ and that $\tilde{\mathbf{M}}_{\mathbf{q q}}=1 / M \mathbf{M}_{\mathbf{q q}}$ (see (56)), we have

$$
\mathbf{D}_{\mathbf{q q}} \tilde{\mathbf{M}}_{\mathrm{qq}} \mathbf{t}=-(\theta / \mathrm{M})(\mathbf{c}-\boldsymbol{\omega})
$$

The Antonelli matrix $\left\{D_{i j}\right\}$ is the generalised inverse of the Slutsky matrix $\left\{\tilde{M}_{i j}\right\}$, i.e.

$$
\mathbf{D}_{\mathbf{q q}} \tilde{\mathbf{M}}_{\mathbf{q q}}=I-\tilde{\mathbf{q}} \mathbf{c}^{\prime}
$$

We therefore have

$$
\left(I-\tilde{\mathbf{q}} \mathbf{c}^{\prime}\right) \mathbf{t}=-(\theta / \mathrm{M})(\mathbf{c}-\boldsymbol{\omega})
$$

and thus that 


$$
\mathbf{t}=\tilde{\mathbf{q}} \mathbf{c} ' \mathbf{t}-(\theta / M) \mathbf{D}_{\mathbf{q q}}(\mathbf{c}-\boldsymbol{\omega})
$$

Since $\mathbf{D}_{\mathbf{q q}} \mathbf{c}=0$

$$
\mathbf{t}=\tilde{\mathbf{q}} \mathbf{c}^{\prime} \mathbf{t}+(\theta / \mathrm{M}) \mathbf{D} \mathbf{\omega}
$$

Substituting by the government's budget constraint, $(\mathbf{c}-\boldsymbol{\omega})$ ' $\mathbf{t}=G$, we get

$$
\mathbf{t}=\tilde{\mathbf{q}}\left(G+\boldsymbol{\omega}^{\prime} \mathbf{t}\right)+(\theta / \mathrm{M}) \mathbf{D} \boldsymbol{\omega}
$$

Multiplying by $\boldsymbol{\omega}$ ' we have

$$
\boldsymbol{\omega}^{\prime} \mathbf{t}=\boldsymbol{\omega}^{\prime} \tilde{\mathbf{q}}\left(G+\boldsymbol{\omega}^{\prime} \mathbf{t}\right)+(\theta / \mathrm{M}) \boldsymbol{\omega} ' \mathbf{D} \boldsymbol{\omega}
$$

Assuming as a matter of normalisation that labour is untaxed, i.e. $t_{0}=0$, and thus that $\boldsymbol{\omega}^{\prime} \mathbf{t}=0$, we have

$$
0=\boldsymbol{\omega}^{\prime} \tilde{\mathbf{q}} G+(\theta / \mathrm{M}) \boldsymbol{\omega}^{\prime} \mathbf{D} \boldsymbol{\omega}
$$

The household's budget constraint is $\boldsymbol{\omega}$ ' $\tilde{\mathbf{q}}=1$; thus

$$
\theta / M=-\frac{G}{\boldsymbol{\omega}^{\prime} \mathbf{D} \boldsymbol{\omega}}
$$

Since $\boldsymbol{\omega}=\left(\omega_{0}, 0,, 0\right)$

$$
\omega_{0} \theta / M=\frac{G}{D_{00}(\mathbf{c}, u) \omega_{0}}
$$

Substituting in (66) by (70), the necessary conditions for an optimal tax may be written as

$$
t_{k}=G \tilde{q}_{k}+\frac{G}{D_{00} \omega_{0}} D_{0 k}
$$

Since $\mathbf{M}=q_{0} \omega_{0}$ we obtain

$$
t_{k}=\tilde{q}_{k}\left(G+\frac{D_{0 k} / \tilde{q}_{0} \tilde{q}_{k}}{D_{00} / \tilde{q}_{0} \tilde{q}_{0}}\right)
$$

Substituting using the definitions of $\rho_{i j}$, we have (cf. Deaton 1981b)

$$
\frac{t_{k}}{q_{k}}=\frac{G}{M}\left(1+\frac{\rho_{k 0}}{\rho_{00}}\right)
$$

or for comparison with (50) 


$$
\frac{t_{j}}{p_{j}} / \frac{t_{k}}{p_{k}}=\left(\frac{\rho_{00}+\rho_{j 0}}{\rho_{00}+\rho_{k 0}}\right)
$$

Assuming that all $-\rho_{00}>\rho_{j 0}>0$ are positive, it follows that the commodity which is most $q$ complementary with leisure will be taxed at the highest rates. Note that the smaller is $\rho_{00}$ numerically, the greater is the concavity of the indifference surface and hence the cost of distorting the relative prices of the produced comodities. Thus, the smaller is $\rho_{00}$, numerically, the greater is the role of Objective 1, to encourage the labour supply, in determining the optimal tax rates. Note also that the ranking of the tax rates is independent of the rule of normalisation adopted.

We are therefore able to convey an intuitive, yet rigorous explanation of what determines the optimal tax system as conjectured in Section 4 as follows

Proposition 5: The optimal tax system represent a compromise between two objectives: First, that of not distorting the pattern of consumption of the produced commodities (Objective 2), represented by $\rho_{00}$, and second, that of discouraging the untaxed consumption of the primary factor (Objective 1), represented by $\rho_{j 0}-\rho_{k 0}$.

The analysis has thus made clear that the appropriate concept of complementarity in relation to the interpretation of optimal tax formulae which may be expressed using Antonelli elasticities of substitution. This seems not generally to have been recognised.

\subsection{The optimal tax structure in the case of a Becker approach the representation of household production ${ }^{12}$}

Atkinson and Stern (1980, 1981) used a Stone-Geary utility function augmented taxation. This utility function may be considered as a special case of the utility function with explicit representation of time specified in Equation (32), where $U\left(c_{0}^{0}, C_{1}, C_{2}, \ldots, C_{\mathrm{N}}\right)$ is a StoneGeary utility function and $C_{i}\left(x_{i}, c_{0}^{1}\right), i \in C$ are Leontief functions ${ }^{13}$. The corresponding expenditure function is

$$
\begin{aligned}
E(\mathbf{q}, u) & \equiv \tilde{E}\left(q_{0}, Q_{1}\left(q_{0}, q_{1} ; \alpha_{1}\right), Q_{2}\left(q_{0}, q_{2} ; \alpha_{2}\right), . . Q_{N}\left(q_{0}, q_{2} ; \alpha_{N}\right) ; \gamma_{i}, i \in F C, \beta_{i}, i \in F C, u\right) \\
& \equiv \sum_{i \in \mathrm{C}}\left(q_{i}+\left(1-\alpha_{i}\right) q_{0}\right) \gamma_{i}+\prod_{i \in \mathrm{C}}\left(q_{i}+\left(1-\alpha_{i}\right) q_{0}\right)^{\beta_{i}}
\end{aligned}
$$

where $\gamma_{i}$ and $\beta_{i}$ are parameters of the Stone Geary utility function. Estimating this functional form on British survey data for Atkinson and Stern (1980, 1981) discovered significant difference in the time requirement of different goods (high for tobacco, low for services).

\footnotetext{
12 This section was written based on Munk (2000a and 2000b) prior to Kleven (2004), see Munk (2001).

${ }^{13}$ However, this utility functions is not as the assumed in Section 2 differentiable.
} 
The advantage of this specification is that it easy to estimate, but it seems too restrictive to be suitable for tax reform analysis. To see this consider the general formulation of the utility function with explicit representation of the use of time, (32), and a proportional tax system, $\frac{p_{i}+t_{i}}{p_{i}}=T>1, i \in F C$, based on the consumption of all commodities, including leisure. Such a tax system is, as we have seen, a first-best solution whatever the structure of the household's preferences. Such a tax system involves higher consumer prices, $\mathbf{q} " \equiv\left(T p_{0}, T p_{1}, . . T p_{\mathrm{N}}\right)$, and thus higher prices for composite commodities, $Q_{i} "=Q_{i}\left(T p_{0}, T p_{i}\right), i \in \mathrm{C}$ than the first-best solution based on lump sum taxation where the prices for composite commodities are $Q_{i}{ }^{\prime}=Q_{i}\left(p_{0}, p_{i}\right), i \in C$.

If we impose the constraint that leisure cannot be taxed, i.e. that $q_{0}=p_{0}$, it is, as we have seen in Section 3, in general not possible to achieve the first-best solution. Although it is possible to choose tax rates for produced commodities to generate prices for composite commodities which create no distortion between the composite commodities such tax rates will involve higher prices for produced commodities relative to the price of non-market use of time. Distorting the allocation between the consumption of produced commodities and time within the aggregation functions for the composite commodities, $C_{i}\left(x_{i}, c_{0}^{i}\right), i \in C$, therefore in general results in a second best solution.

However, considering the intrinsically not very interesting case where all the aggregation functions for the composite commodities, $C_{i}\left(x_{i}, c_{0}^{i}\right), i \in C$, are Leontief (and thus not differential as assumed in Section 2), and where the household's consumption of pure leisure, $c_{0}^{0}$, is nil ${ }^{14}$, distorting the price ratio between produced commodities and time does not distort the allocation, as pointed out by Kleven (2000). A tax vector where leisure is untaxed will therefore establish a first-best solution if the tax rates on produced commodities are chosen so that the relative prices for the composite commodities are the same as if the government's resource requirement had been financed by a proportional tax system based on the consumption on all commodities, i.e. if

$$
Q_{i}\left(p_{0}, p_{i}+t_{i}\right)=Q_{i}\left((1 /(1-\tau)) p_{0},(1 /(1-\tau)) p_{i}\right)
$$

where $\tau<1$ is the rate of tax on the household's endowment of time net of the fixed amount used for pure leisure required to finance the government's resource requirement. Since for this utility function the aggregation functions are Leontief

$$
Q_{i}^{\prime}=1 /(1-\tau)\left(q_{0}\left(1-a_{i}\right)+p_{i} a_{i}\right)=\left(q_{0}\left(1-a_{i}\right)+\left(q_{i}+t_{i}\right) a_{i}\right)
$$

Therefore assuming $t_{0}=0$ as a matter of normalisation, we see that

$$
\frac{t_{i}}{q_{i}}=\frac{\tau}{1-\tau} \frac{1}{a_{i}}
$$

\footnotetext{
${ }^{14}$ This is the case if $U\left(c_{0}^{0}, C_{1}, C_{2}, . ., C_{\mathrm{N}}\right)$ is Leontief or if the household consumes no pure leisure.
} 
is a first-best solution and thus that



$k, j \in \mathrm{C}(80)$

Commodities that require relative much time for their consumptions, i.e. where $a_{i}$ is relatively small, is thus taxed at a relatively high rates.

Kleven (2000) derives a formula similar to (80) from the government's problem of maximising the utility of a representative household subject to constraints representing the government's budget and household production and by assuming that the household consumes no pure leisure. However his derivation was somewhat flawed ${ }^{15}$, and the method used in Kleven (2004) is similar to the one used here. Furthermore, inspired by Myles (1995, p124) ${ }^{16}$, due to lack of understanding of the proper rules of normalisation Kleven (2000) fails to interpret this formula as equivalent to a proportional tax system based on the consumption of all commodities, as in Munk (2000a and 2000b).

The functional form used by Atkinson and Stern (1980) for tax reform analysis therefore implies that the optimal solution is first best, in other words that the solution need not be associated with distortionary costs even when lump taxation is not available to the government. In general this is not an assumption one would like to make in tax reform analysis.

${ }^{15}$ From the government's problem of maximising the utility of a representative household subject to constraints
representing the government's budget and household production Kleven (2000) derives a formula (formulated in
our notation) $\frac{t_{k}}{q_{k}} \varepsilon_{k k}^{1}+\sum_{i \in c} \frac{t_{i}}{q_{i}} a_{i} \varepsilon_{k i}^{2}=-\theta, k \in C$, and then derives (80) from this expression assuming a Becker type representation of household production, i.e. that $\varepsilon_{k k}^{1}=0, k \in C$. Strictly speaking this cannot be done as in the case of a Leontief specification of the aggregation functions for the composite commodities, $C_{i}\left(x_{i}, c_{0}^{i}\right), i \in C$, the solution to the government's maximisation problem is first best and thus $\theta=0$.

${ }^{16}$ Myles (1995, p124) writes "It has been shown that in an economy with constant returns to scale consumer and producer prices can be normalised separately and that standard procedure is to make one good the numeraire and set the consumer and producer prices equal. This normalisation also has the effect of setting the tax on that good to zero. In particular, the zero tax is just a result of the normalisation rule. In particular, the zero tax carries no implication about the nature of the good nor about the ability to tax that good. This follows since the good with zero tax can be chosen arbitrarily from the set of available goods. Unfortunately, this reasoning has not been as clearly appreciated in some literature, it has been inferred from this that, since leisure cannot be measures in the same way as purchase of other commodities can, the zero tax on leisure is a restriction on the permissible tax system brought about by an inability to tax leisure. In addition the further inference is usually made that the optimal tax system aims to overcome this missing tax on the leisure by taxing goods complementary to leisure. Particular examples of this is found in the Corlett and Hague (1953) by 'taxing those goods complementary with leisure, one is to some extent taxing leisure itself' (p. 26) and Layard and Walters (1978) 'the theory of second best tells us that if we cannot tax leisure we can do better than by taxing all goods equiproportionally' (p. 184). Many other instances of similar statements could easily be given. This of course is a false interpretation. When real restrictions upon the permissible range of tax instruments are introduced the result obtained are affected. A number of such restrictions are considered in Munk (1980) where it is shown that the resulting optimal tax structure is sensitive to the precise restrictions imposed" 


\section{Quantitative illustration}

\subsection{The CES-UT utility function}

Figure 3: The structure of the CES-UT utility function for $N=2$

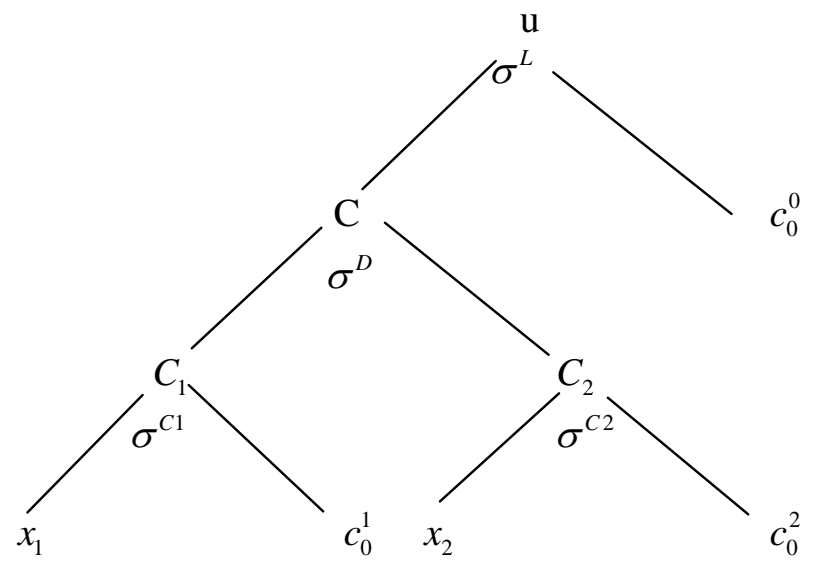

The parameterised utility function, CES-UT is defined as (cf. Munk 1998, Annex 1)

$$
U\left(c_{0}^{0}, C\left(C_{1}\left(x_{1}, c_{0}^{1} ; \sigma^{11}\right), C_{2}\left(x_{2}, c_{0}^{2} ; \sigma^{12}\right), \ldots, C_{\mathrm{N}}\left(x_{\mathrm{N}}, c_{0}^{\mathrm{N}} ; \sigma^{1 \mathrm{~N}}\right) ; \sigma^{2}\right) \sigma^{3}\right)
$$

where $C_{i}\left(x_{i}, C_{0}^{i} ; \sigma^{1 i}\right), i \in \mathrm{C}, C\left(C_{1}, C_{2}, . ., C_{\mathrm{N}} ; \sigma^{2}\right)$ and $U\left(C, C_{0}^{0} ; \sigma^{3}\right)$ are CES functions characterised by elasticities of substitution $\sigma^{1 i}, i \in C, \sigma^{2}$ and $\sigma^{3}$, respectively. The structure of the CES-UT is illustrated in Figure 3.

We want to demonstrate that the CES-UT is quite flexible with respect to representation of household preferences in particular, allowing different commodities to have different degrees of complementarity with leisure.

Differentiating (14) we get the corresponding demand system

$$
\begin{aligned}
& x_{i}(\mathbf{q}, u)=\frac{\partial \tilde{E}}{\partial Q} \frac{\partial Q}{\partial Q_{i}} \frac{\partial Q_{i}}{\partial q_{i}} \\
& x_{0}(\mathbf{q}, u)=\frac{\partial \tilde{E}}{\partial q_{0}}+\frac{\partial \tilde{E}}{\partial Q} \sum_{j \in \mathrm{C}} \frac{\partial Q}{\partial Q_{j}} \frac{\partial Q_{j}}{\partial q_{0}}-\omega_{0}
\end{aligned}
$$

We define

$$
\begin{array}{lll}
\varepsilon_{i i}^{1} \equiv \frac{\partial^{2} Q_{i}}{\partial q_{i} \partial q_{i}}\left(q_{i}, q_{0}\right) C_{i} / \frac{x_{i}}{q_{i}} ; & -\varepsilon_{i 0}^{1} \equiv \frac{\partial^{2} Q_{i}}{\partial q_{i} \partial q_{0}}\left(q_{i}, q_{0}\right) C_{i} / \frac{x_{0}}{q_{i}} & i \in \mathrm{C} \\
\varepsilon_{i j}^{2} \equiv \frac{\partial^{2} Q}{\partial Q_{i} \partial Q_{j}}\left(Q_{1}, Q_{2}, ., Q_{\mathrm{N}}\right) C / \frac{C_{i}}{Q_{j}} & & i, j \in \mathrm{C}
\end{array}
$$




$$
\begin{aligned}
& \varepsilon_{c C}^{3} \equiv \frac{\partial^{2} E^{2}}{\partial Q \partial C}\left(q_{0}, Q, u\right) / \frac{C}{Q} ; \quad-\varepsilon_{c 0}^{3} \equiv \frac{\partial^{2} E^{2}}{\partial Q \partial \mathrm{q}_{0}}\left(q_{0}, Q, u\right) / \frac{x_{0}}{Q} \\
& \alpha_{i} \equiv \frac{q_{i} x_{i}}{q_{0} x_{0}}
\end{aligned}
$$

Differentiating with respect to $q_{j}$ and $q_{0}$, respectively, and defining $a_{j} \equiv \frac{q_{j} X_{j}}{Q_{j} C_{j}}$ as the share of the costs of the consumption of commodity $j$ in the total costs of composite $j$ (which include the cost of the consumption of time) and $b_{j} \equiv \frac{Q_{j} C_{j}}{Q C}$ the share of the composite $j$ in the total cost of consumption (including the consumption of time except pure leisure), we get

$$
\begin{array}{rlrl}
\varepsilon_{i i}=\varepsilon_{i i}^{1}+a_{i} \varepsilon_{i i}^{2}+a_{i} b_{i} \varepsilon_{c C}^{3} & i \in C \text { (84) } \\
\varepsilon_{i j}=a_{j} \varepsilon_{i j}^{2}+a_{j} b_{j} \varepsilon_{c C}^{3} & j \neq i \in C \text { (85) } \\
\varepsilon_{i 0}=\varepsilon_{i 0}^{1}+\sum_{j \in \mathrm{C}}\left(1-a_{j}\right) \varepsilon_{i j}^{2}+\sum_{j \in \mathrm{C}} a_{j} b_{j} \varepsilon_{c 0}^{3} & i \in C(86)^{17} \\
\varepsilon_{0 i}=\alpha_{i}\left(\varepsilon_{i 0}^{1}+\sum_{j \in \mathrm{C}}\left(1-a_{j}\right) \varepsilon_{i j}^{2}+\sum_{j \in \mathrm{C}} a_{j} b_{j} \varepsilon_{c 0}^{3}\right) & i \in C \text { (87) }
\end{array}
$$

In the case of the CES-UT, $\varepsilon_{i i}^{1}=\varepsilon_{i 0}^{1}=-\left(1-a_{i}\right) \sigma^{1 i}, \varepsilon_{i j}^{2}=b_{j} \sigma^{2}$ for $i, j \neq i \in \mathrm{C}$

$$
\begin{array}{rlr}
\varepsilon_{i i}^{2}=-\left(1-b_{i}\right) \sigma^{2} \text { for } i \in C \text { and } \varepsilon_{c c}^{3}=-\varepsilon_{c 0}^{3}=-(1-c) \sigma^{3}, & \text { where } c \equiv \frac{Q C}{q_{0} c_{0}^{0}+Q C} \text {, we have } \\
& \varepsilon_{i i}=-\left(1-a_{i}\right) \sigma^{1 i}-a_{i}\left(1-b_{i}\right) \sigma^{2}-a_{i} b_{i}(1-c) \sigma^{3} & i \in C(88) \\
& \varepsilon_{i j}=a_{j} b_{j} \sigma^{2}-a_{j} b_{j}(1-c) \sigma^{3} & i, j \in C(89) \\
& \varepsilon_{i 0}=\left(1-a_{i}\right) \sigma^{1 i}+\left(a_{i}-\bar{a}\right) \sigma^{2}-\bar{a}(1-c) \sigma^{3} & i \in C(90) \\
& \varepsilon_{0 i}=\alpha_{i}\left(\left(1-a_{i}\right) \sigma^{1 i}+\left(a_{i}-\bar{a}\right) \sigma^{2}-\bar{a}(1-c) \sigma^{3}\right) & i \in C(91)
\end{array}
$$

where $\bar{a}=\sum_{i \in C} a_{i} b_{i}$.

It is thus possible to link the parameters of the CES-UT with estimates of $\varepsilon_{i j}, i, j \in F C$, readily available from econometric estimates of flexible functional forms (which however cannot be used in simulation studies because they globally do not satisfy the assumptions of quasi-concavity and monotonicity).

The elasticities of substitution between the commodities and leisure, $\sigma_{i o}, \quad i \in C$, are related to the compensated elasticities by $\varepsilon_{i 0}=s_{0} \sigma_{i o}$ where $s_{0}$ is the share of labour income in full

\footnotetext{
${ }^{17}$ This formula may alternatively be derived from using that $\varepsilon_{i 0}=-\sum_{j \in \mathrm{C}} \varepsilon_{i j}$ and $\varepsilon_{i 0}^{1}=-\varepsilon_{i i}^{1}$ and $\varepsilon_{c 0}^{3}=-\varepsilon_{c c}^{3}$.
} 
income, $q_{0} \omega_{0}$. Differences in $\varepsilon_{i 0}$ therefore reflect differences in the complementarity with leisure of the different commodities.

The compensated elasticity of commodity $i$ with respect to the price of labour, $\varepsilon_{i 0}$, depends on three elements (see (86)): The within element, the between element and the pure leisure element.

The within element is represented by the first term, is given by $\varepsilon_{i 0}^{1}=\left(1-a_{i}\right) \sigma^{1 i}$. This element is always positive with respect to the value of $\varepsilon_{i 0}$, and is larger, the larger the amount of time used for the consumption of commodity $i,\left(1-a_{i}\right)$, and the larger the elasticity of substitution between time and the commodity within the composite commodity $i, \sigma^{1 i}$.

The between element is represented by the second term: $\sum_{j \in \mathrm{C}}\left(1-a_{j}\right) \varepsilon_{i j}^{2}=\left(a_{i}-\bar{a}\right) \sigma^{2}$. This element may be positive or negative with respect to the value of $\varepsilon_{i 0}$ depending on whether commodity $i$ requires a relatively large amount of time for its consumption, i.e. $a_{i}<\bar{a}$, or relatively small amount, i.e. $a_{i}>\bar{a}$. In the first case, an increase in the price of the commodity and hence in the corresponding composite commodity results in a shift to composite commodities which involve the use of relatively less time, drawing in the direction of a small $\varepsilon_{i 0}$; in the second case the opposite will be the case, drawing in the direction of a relatively large $\varepsilon_{i 0}$. The elasticity between composite commodities, $\sigma^{2}$, amplifies the effect whatever its direction.

The pure leisure element is represented by the third term: $\bar{a}(1-c) \sigma^{3}$ is always positive with respect to the value of $\varepsilon_{i 0}$. Furthermore the larger the share of the household's time endowment used for pure leisure $(1-c)$ and the larger the elasticity of substitution between leisure and consumption, $\sigma^{3}$, the larger is this element.

In particular we see that

1) for $a_{i}>\bar{a}$, i.e. when a relatively small amount of time is used for the consumption of commodity $i$, then relatively large substitution elasticities $\sigma^{1 i}, \sigma^{2}$ imply relatively large $\varepsilon_{i 0}$, and

2) for $\sigma^{2}>\sigma^{1 i}$, i.e. when the between element dominates, then a relatively large amount of time, $\left(1-a_{i}\right)$, used for the consumption of commodity $i$ imply a relatively small $\varepsilon_{i 0}$, but

3) for $\sigma^{2}<\sigma^{1 i}$, i.e. when the within element dominates, then a relatively large amount of time, $\left(1-a_{i}\right)$, used for the consumption of commodity $\underline{i}$ implies a relatively large $\varepsilon_{i 0}$. 
Indicators for Objective 1 and 2 (see Section 6.2) becomes, respectively

$$
\begin{aligned}
& \mathrm{I}_{1}=\left(1-a_{1}\right) \sigma^{11}+\left(1-a_{1}\right) \sigma^{12}+\left(a_{1}\left(1-b_{1}\right)+a_{2}\left(1-b_{2}\right)\right) \sigma^{2}+\left(a_{1} b_{1}+a_{2} b_{2}\right)(1-c) \sigma^{3} \\
& \mathrm{I}_{2}=\left(a_{1}-a_{2}\right) \sigma^{2}+\left(1-a_{1}\right) \sigma^{11}-\left(1-a_{2}\right) \sigma^{12}
\end{aligned}
$$

where

$a_{j} \equiv \frac{q_{j} X_{j}}{Q_{j} C_{j}}$ :share of the costs of the consumption of commodity $j$ in the total costs of composite $j$

$b_{j} \equiv \frac{Q_{j} C_{j}}{Q C}$ : the share of the composite $j$ in the total cost of consumption

$c \equiv \frac{Q C}{q_{0} c_{0}^{0}+Q C}$ :share of consumption in full income

$\bar{a}=\sum_{i \in C} a_{i} b_{i}$

\subsection{Quantitative results for alternative sets of parameter values}

\section{Table 1: Parameters}

\begin{tabular}{l|c|c|c|c|c}
\hline & & Set 1 & Set 2 & Set 3 & Set 4 \\
\hline $\begin{array}{l}\text { Elasticity of substitution between commodity } \\
1 \text { and the time used for its consumption }\end{array}$ & $\sigma^{11}$ & 0,00 & 0,20 & 0,00 & 0,20 \\
\hline $\begin{array}{l}\text { Elasticity of substitution between commodity } \\
2 \text { and the time used for its consumption }\end{array}$ & $\sigma^{12}$ & 0,00 & 0,20 & 0,00 & 0,20 \\
\hline $\begin{array}{l}\text { Elasticity of substitution between the } \\
\text { composite commodities }\end{array}$ & $\sigma^{2}$ & 0,50 & 0,00 & 0,50 & 0,20 \\
\hline $\begin{array}{l}\text { Elasticity of substitution between } \\
\text { consumption and pure leisure }\end{array}$ & $\sigma^{3}$ & 0,50 & 0,50 & 0,50 & 0,50 \\
$\begin{array}{l}\text { Share of time in composite commodity 1 } \\
\text { in benchmark }\end{array}$ & $a_{1}$ & $1 / 7$ & $1 / 7$ & $1 / 7$ & $1 / 7$ \\
\hline $\begin{array}{l}\text { Share of time in composite commodity } 2 \\
\text { in benchmark }\end{array}$ & $a_{2}$ & $1 / 2$ & $1 / 2$ & $1 / 2$ & $1 / 2$ \\
\hline $\begin{array}{l}\text { Share of pure leisure as share of full income } \\
\text { (1-c) }\end{array}$ & 0,00 & 1,00 & 1,00 & 1,00 \\
\hline
\end{tabular}

The benchmark data and the parameters specified imply that the value of the household's endowment is 300

Since the governments requirement is 50, a tax on the value of endowment at rate $\tau=1 / 6$ would therefore be sufficient to raise the revenue required for the government without distorting the resource allocation 
In the case of such a tax, the real income for the household would be 100

\section{Optimal tax system for Parameter set 1 (Leontief):}

Assuming that the share of full income spent on pure leisure, 1-c, is fixed at 0 and that the elasticities of substitution within the commodity composites, $\sigma^{11}$ and $\sigma^{12}$ are fixed at 0 , there are no scope for substitution between consumption of produced commodities and leisure within the commodity composites and between aggregate consumption and pure leisure. Assuming $t_{0}=0$ as a matter of normalisation the optimal tax rates are therefore

$$
\begin{aligned}
& t_{1}=\frac{\tau}{1-\tau} \frac{1}{a_{1}}=1,40 \\
& t_{2}=\frac{\tau}{1-\tau} \frac{1}{a_{2}}=0,40
\end{aligned}
$$

For this set of parameters the optimal solution is first-best, although lump sum taxation is not possible. The intuitive explanation is that it effectively raises the price of time by the same amount for all uses as had the revenue been raised directly by a tax on the household's endowment. At the optimum there is therefore no conflict between the two objectives.

\section{Optimal tax systems for Parameter sets 2-4:}

$I_{1}$, the indicator for Objective 1 (Distortion of the pattern of consumption of produced commodities) increases with increasing elasticities of substitution, $\sigma^{11}, \sigma^{12}, \sigma^{2}, \sigma^{3}$. The larger the elasticities, the larger the distortionary costs of a differentiated tax structure.

$I_{2}$, the indicator for Objective 2 (Increasing the supply of labour) increases with increasing elasticities of substitution, $\sigma^{11}, \sigma^{12}, \sigma^{2}$. However, how the effect on the labour supply depend on $\sigma^{11}, \sigma^{12}, \sigma^{2}$ is complex. To facilitate the interpretation of the optimal tax formulae we therefore consider the less general case where $\sigma^{11}=\sigma^{12}=\sigma^{1}$. Then

$$
\begin{aligned}
& I_{1}=\varepsilon_{11}+\varepsilon_{22}=-\left(2-a_{1}-a_{2}\right) \sigma^{1}-\left(a_{1}+a_{2}-\bar{a}\right) \sigma^{2}-\bar{a}(1-c) \sigma^{3} \\
& I_{2}=\varepsilon_{10}-\varepsilon_{20}=-\left(a_{1}-a_{2}\right) \sigma^{1}+\left(a_{1}-a_{2}\right) \sigma^{2}
\end{aligned}
$$

The first term, $-\left(a_{1}-a_{2}\right) \sigma^{1}$, the within effect, is the substitution effect within the composite aggregation functions, $C_{1}\left(x_{1}, c_{0}^{1}\right)$ and $C_{2}\left(x_{2}, c_{0}^{2}\right)$. This effect is positive (i.e. the effect on the supply of labour is negative) if $a_{1}<a_{2}$. The second effect, $\left(a_{1}-a_{2}\right) \sigma^{2}$, the between effect, is due to the substitution between composite commodities within the aggregation function $C\left(C_{1}, C_{2}\right)$. This effect is negative (i.e. the effect on the supply of labour is positive) if $a_{1}<a_{2}$. 
The relative strength of the two effects determines the sign of $I_{2}$, and thus which commodity is taxed at the highest rate.

For example, for $\sigma^{2}=0$ we have because the second effect dominates,

$$
\frac{t_{1} / q_{1}}{t_{2} / q_{2}}=\frac{\left(1-a_{2}\right)}{\left(1-a_{1}\right)}<1
$$

Conversely for $\sigma^{1}=0$ we have because the first effect dominates

$$
\frac{t_{1} / q_{1}}{t_{2} / q_{2}}=\frac{a_{2}}{a_{1}}>1
$$

For $\sigma^{1}=\sigma^{2}$ the two effects balance each other out,

$$
\frac{t_{1} / q_{1}}{t_{2} / q_{2}}=1
$$

Table 2: Indicators for objective 1 and 2 and the corresponding optimal relative tax rates

\begin{tabular}{|c|c|c|c|}
\hline & $\begin{array}{c}\text { Indicator for } \\
\text { Objective 1. } \\
\mathrm{I}_{1}\end{array}$ & $\begin{array}{c}\text { Indicator for } \\
\text { Objective 2. } \\
\mathrm{I}_{2}\end{array}$ & $\begin{array}{c}\text { Optimal relative tax } \\
\text { rates } \\
t_{1} / t_{2}\end{array}$ \\
\hline Set 1 & 0,180 & $-0,150$ & 3,50 \\
\hline Set 2 & 0,330 & 0,080 & 0,38 \\
\hline Set 3 & 0,280 & $-0,150$ & 3,45 \\
\hline Set 4 & 0,390 & 0,000 & 1,00 \\
\hline
\end{tabular}

It is intuitively plausible that the commodity, which requires the relatively largest amount of time for its consumption, is relatively most complementary with leisure and therefore should be taxed at the highest rate. However, as the analysis of the CES-UT illustrates, this intuition may be misleading. In the situation where the substitution possibilities within the timeconsumption composites are relatively large the indicator for Objective 2 will be greater than 1 if the share of time in composite 1 is smaller than in composite 2 . In this case commodity 1 , which uses a relatively small amount of time for its consumption, will be taxed at a relatively high rate. 
Table 3: Optimal tax rates for alternative sets of parameter values

\begin{tabular}{|l|r|r|c|c|c|}
\hline Results & & Set 1 & Set 2 & Set 3 & Set 4 \\
\hline Tax on labour & $t_{0}$ & 0,00 & 0,00 & 0,00 & 0,00 \\
\hline Tax on consumption of commodity 1 & $t_{1}$ & 1,40 & 0,22 & 1,45 & 0,55 \\
\hline Tax on consumption of commodity 2 & $t_{2}$ & 0,40 & 0,58 & 0,42 & 0,55 \\
\hline Labour supply & $-x_{0}$ & 150,00 & 142,30 & 146,42 & 141,52 \\
\hline Consumption commodity 1 & $x_{1}$ & 10,00 & 9,29 & 9,64 & 9,15 \\
\hline Consumption commodity 2 & $x_{2}$ & 90,00 & 83,00 & 86,78 & 82,37 \\
\hline Real income & & 100,00 & 98,21 & 99,17 & 98,02 \\
\hline
\end{tabular}

It is thus relatively easy by specifying different values of the parameters of the CES-UT, $a_{i}$, $\sigma^{1 i}, \sigma^{2}$, to represent different degrees of complementarity with leisure for the different commodities. In contrast to the additive separable utility functions, as the CES, the CES-UT therefore allows the complementarity with leisure to differ between commodities. Furthermore each of the parameters of the CES-UT has a clear economic interpretation, facilitating the intuitive understanding of the relation between the parameters and the elasticities.

\section{Concluding remarks and summary}

The standard model used for tax reform and optimal tax analysis which emerged in the 70ties assumes labour to be untaxed. However, in the presence of (untaxed) profit and when households' consumption of their primary factor endowment can be taxed, this assumption cannot be considered a rule of normalisation in the sense that it does not imply any loss of generality. Dixit and Munk (1977) reinterpreted the analytical results in Dixit (1970) and Dixit (1975) taking into account the first point concerning untaxed profit. The present paper deals with the second point where the households' endowment can be taxed. Although the analysis of this particular case in itself is of little practical importance, the ambiguity with respect to normalisation seems to have created a barrier for the proper understanding of what determines desirable directions of tax-reform and optimal systems of commodity taxation in the subsequent literature by confusing the issue of normalisation. As indicated above an example of this in an influential and widely used textbook on Public Economics is Myles (1995).

Much applied work, and in particular work based on the use of general equilibrium models, adds structure to the general representation of household preferences by employing additively separable utility functions. However, seen from the point of view of the theory of optimal taxation this representation of household behaviour severely limits the flexibility of the resulting demand system. When only efficiency considerations matter, the assumption of additively separable utility functions implies that optimality requires taxation of all produced commodities at a uniform rate or, equivalently, only a proportional tax on the households supply of labour to the market. As eloquently put by Deaton (1981a, p1) "it is likely that empirically calculated tax rates, based on econometric estimates of parameters, will be 
determined in structure, not by the measurement actually made, but by arbitrary untested (and even unconscious) hypothesis chosen by the econometrician for practical convenience”. This motivated Atkinson and Stern $(1980,1981)$ to employ a Stone-Geary utility function augmented with the explicit representation of the use of time according to the Becker (1965) theory of household production. Importantly, they drew attention to the results established by Pollack and Wachter (1975), that when incorporating household production in the utility function, the standard theory of demand still apply. They estimated based on British survey data a demand system which they used to evaluate the implication of a switch from direct to indirect taxation. However, although they justified their approach with the importance for the optimal tax system of the interaction of consumption with leisure, they did not take their analysis to its logical conclusion. They neither did investigate whether a tax reform involving higher taxes on goods with high time requirement would increase welfare, nor did they derive optimal tax rates for the demand system they estimated. Their choice of a Leontief specification of the relationship between the use of time and consumption, inherent in the Becker approach, is attractive in that it allows the estimation of a complete system of household demand based only on panel data but very restrictive. A much less restrictive and still computationally manageable alternative is to represent the relationship between the use of time and consumption of purchased commodities by a constant elasticity of substitution (CES) functions rather that by Leontief functions. This specification has been employed to analyse the optimal support to low income household (Munk 1998), the welfare implication of green tax reform (Munk 1999) and recently to illustrate the importance of the size of the informal sector for the desirability of using border taxes in developing countries Munk (2004, 2008).

We have drawn attention to the importance of the distinction between the behavioural assumption that the consumption of the primary factor cannot be taxed and the assumption that the supply of the primary factor to the market is untaxed. The former assumption constrains the set of feasible solutions, while the latter does not. We have explained why ambiguity with respect to this distinction has created a barrier for identification of what constitute desirable directions of tax reform, and thus for what determines the optimal tax system. Reviewing Dixit (1975)'s original analysis, we have provided an intuitive explanation of what determines the optimal tax system as a trade-off between two objectives: 1) the objective of not distorting the consumption of produced commodities, and 2) the objective of encouraging the supply of labour, emphasising that this insight does not depends on the choice of numeraire as has been suggested. In recasting Deaton's important but largely neglected work on using the distance function for optimal tax analysis, we have brought out this interpretation in the case of many produced commodities. Finally, we have thus in the spirit of the endeavour by Atkinson and Stern $(1980,1981)$ provided a parameterisation of a utility function with the explicit representation of the use of time, the CES-UT, which may be used to illustrate this trade-off. This may in applied work be used as an alternative to functional forms, which as they impose separability between consumption and leisure, may result in misleading conclusions from tax simulations studies. 


\section{References}

Atkinson, A. B. and N.H. Stern (1980), “On the switch from direct to indirect taxation” Journal of Public Economics, 14, 195-22

Atkinson, A. B. and N. Stern (1981), “On labour supply and commodity demands”, in A.S. Deaton, (ed.) Essays in the Theory and Measurement of Consumer Behaviour, Cambridge University Press, Cambridge

Becker, G.S. (1965), “A Theory of the Allocation of Time”, Economic Journal, 75, 493-517

Boadway, R. and F. Gahvari (2006), "Optimal taxation with consumption time as a leisure or labor substitute, Journal of Public Economics, 90, 1851-1878

Corlett, W. J. and D. C. Hague (1953), “Complementarity and excess burden of taxation”, Review of Economic Studies, 21, 21-30

Deaton, A. S. (1981a), Essays in the Theory and Measurement of Consumer Behaviour, Cambridge University Press, Cambridge

Deaton, A. S. (1981b), "Optimal taxes and the structure of preferences", Econometrica, 19, 273-92

Diamond P. A. (1975), “A Many-Person Ramsey Tax Rule”, Journal of Public Economics, 4, 335-342

Diamond, P. And J. Mirrlees (1975), “Optimal taxation and public production (I), American Economic Review, 61, 8-27

Dixit, A. (1970), “On the optimum structure of commodity taxes”, American Economic Review, 60, 295-301

Dixit, A. (1975), "Welfare effect of tax and price changes", Journal of Public Economics, 4, 103-123

Dixit, A. and K. J. Munk (1977), "Welfare effect of tax and price changes. A Correction", Journal of Public Economics, 8, 103-107

Kleven, H. J, W. Richter and P. B. Sørensen (2000), ”Optimal taxation with household production, Oxford Economic Papers, 52, 584-594

Kleven, H. J. (2000), "Optimal taxation and the allocation of time", Paper presented at the $56^{\text {th }}$ Congress of the International Institute of Public Finance, August 2000.

Kleven, H. J. (2004) "Optimal taxation and the allocation of time", Journal of Public Economics, 88, 545-557.

Layard, R and A.A. Walters (1978), “Microeconomic Theory”, McGraw-Hill 
Munk, K. J., (1978), "Optimal Taxation and Pure Profit", Scandinavian Journal of Economics, 80, 1-19.

Munk, K. J., (1980), "Optimal taxation with some none-taxable commodities", Review of Economic Studies, 47, 755-765

Munk, K. J. (1998),"Optimal support to low income households”, Paper presented at the $54^{\text {th }}$ Congress of the International Institute of Public Finance, August 1998, Public Economics Research Paper, CES, KU Leuven, DPS 98.27, EPRU Working Paper1998-20, University of Copenhagen", (under the title "Should Governments Create Production Inefficiency"), Conference volume, Skatteforum 2000, The Research Council of Norway

Munk, K. J. (1999),"A double dividend after all?”, Paper presented at the $55^{\text {th }}$ Congress of the International Institute of Public Finance, August 1999, Public Economics Research Paper, CES, KU Leuven, DPS 99.18, EPRU Working paper 2000-06, University of Copenhagen”, (under the title “Administrative costs and the Double Dividend”)

Munk, K. J. (2000a), "Note on the optimal tax structure in the case of household production with fixed coefficients between time and purchased commodities", unpublished manuscript August 2000, EPRU, University of Copenhagen

Munk, K.J. (2000b), “Normalisation, complementarity with leisure and optimal taxation”, unpublished manuscript, August 2000, EPRU, University of Copenhagen”

Munk, K. J. (2001),"What determines the commodity tax structure from a intuitive point of view", Paper presented at the $57^{\text {th }}$ Congress of the International Institute of Public Finance, August 2001 and at the Workshop on Tax Policy and Public Economics, Uppsala November 2001, EPRU Working paper 2002-17, University of Copenhagen

Munk, K. J. (2004), “Tax-tariff reform with costs of administration,”, Paper presented at the $60^{\text {th }}$ Congress of the International Institute of Public Finance, August 2004. Forthcoming International Tax and Public Finance

Munk, K. J. (2008), “On the use of border taxes in developing countries”, Department of Economics Working Paper, Université catholique de Louvain, Forthcoming

Myles, G. R. (1995) “Public Economics”, Cambridge University Press

Pollak, R.A. and M. L. Wachter (1975), “The relevance of the household production function and its implication for the allocation of time”, Journal of Political Economy, 83, 255-78

Sørensen, P. B. (2007), ”The theory of optimal taxation: what s the policy relevance?, International tax and Public Finance, 14, 383-406 
Département des Sciences Économiques de l'Université catholique de Louvain

Institut de Recherches Économiques et Sociales

Place Montesquieu, 3

1348 Louvain-la-Neuve, Belgique 